

\section{DISCLAIMER}

This report was prepared as an account of work sponsored by an agency of the United States Government. Neither the United States Government nor any agency Thereof, nor any of their employees, makes any warranty, express or implied, or assumes any legal liability or responsibility for the accuracy, completeness, or usefulness of any information, apparatus, product, or process disclosed, or represents that its use would not infringe privately owned rights. Reference herein to any specific commercial product, process, or service by trade name, trademark, manufacturer, or otherwise does not necessarily constitute or imply its endorsement, recommendation, or favoring by the United States Government or any agency thereof. The views and opinions of authors expressed herein do not necessarily state or reflect those of the United States Government or any agency thereof. 


\section{DISCLAIMER}

Portions of this document may be illegible in electronic image products. Images are produced from the best available original document. 
This work was supported by the US Department of Energy, Office of Coordination and Special Projects.

Edited by Jill Warren

Photocomposition by Zian H. Swanson

\section{DISCLAIMER}

This report was prepared as an account of work sponsored by an agency of the United States Government. Neither the United States Government nor any agency thereof, nor any of their employees, makes any warranty, express or implied, or assumes any legal liability or responsibility for the accuracy, completeness, or usefulness of any information, apparatus, product, or process disclosed, or represents that its use would not infringe privately owned rights. References herein to any specific commercial product, process, or service by trade name, trademark, manufacturer, or otherwise, does not necessarily constitute or imply its endorsement, recommendation, or favoring by the United States Government or any agency thereof. The views and opinions of authors expressed herein do not necessarily state or reflect those of the United States Government or any agency thereof. 
LA- $-9078-$ HS

DE82 014121

\section{The Light Weight Radioisotope Heater Unit (LWRHU):}

\section{A Technical Description of the Reference Design}

R. E. Tate

\section{ROTICE}

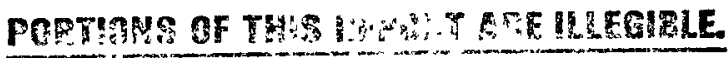

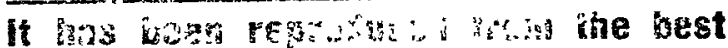

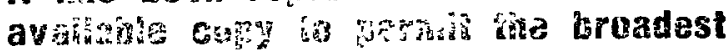

DISCLAIMER

Ne ther the Un brepared as an accuunt of work sponsored by an agency of the Un ted States Governiment possinge avationdis. 


\title{
THE LIGHT WEIGHT RADIOISOTOPE HEATER UNIT (LWRHU): \\ A TECHNICAL DESCRIPTION OF THE REFERENCE DESIGN
}

by

\author{
R. E. Tate
}

\begin{abstract}
The Light Weight Radioisotope Heater Unit (LWRHU), a new radioisotope heater unit for use in space missions, is a ${ }^{238} \mathrm{PuO}_{2}$-fueled unit designed to provide a thermal watt in dispersed locations on a spacecraft. The LWRHU is required to maintain the temperature of a component at a level where the component will function reliably in space. Two major constraints are placed on the unit's design; it must be as light as possible and must provide enough protection to immobilize the plutonium fuel to the maximum extent in all phases of the unit's lifetime. The four components are pelletized fuel, platinum-alloy encapsulation, pyrolytic graphite thermal insulation, and high-technology graphite ablation shell. The LWRHU is a cylinder $32 \mathrm{~mm}$ (1.26 in.) high and $26 \mathrm{~mm}$ (1.02 in.) in diameter. It weighs slightly less than $40 \mathrm{~g}$ (.09 lb).
\end{abstract}

\section{DESIGN OBJECTIVE}

The design objective of the Light Weight Radioisotope Heater Unit (LWRHU) project was to achieve an improved second-generation design for a heat source that produces $1 \mathrm{~W}(\mathrm{t}) 7 \mathrm{yr}$ after fueling and is qualified for space missions. The four-component system is shown in Fig. 1. The unit has low mass and minimum dimensions. Also, it will have an improved safety margin to immobilize the $2.6 \mathrm{~g}$ of ${ }^{238} \mathrm{PuO}_{2}$ fuel in all credible accident situations. Table I presents a tabulation of the more significant requirements. Initially, a tight schedule requiring design, development testing, production, and delivery within 14 months was necessary. Postponement of the Galileo (GLL) and Solar/Polar mission launches permitted more iterations in the design process and resulted in a design with more safety margin.

\section{CRITICAL ENVIRONMENTS}

Three periods in the operational life of the LWRHU present critical environments-launch, launch abort, and earth reentry. We anticipate severe vibration levels at launch, particularly in certain locations such as antenna booms. Only high, conservative estimates of these levels are available for design evaluation and testing. If a launch is aborted, at least some LWRHUs probably will be exposed to blast, to penetration by a fragment projectile, or to a propellant fire. The magnitudes of these destructive forces are not yet well assessed. If earth reentry were to occur, the critical enviroments are rapid thermal heating, ablation of the aeroshell, and impact at moderately high velocity. A worst case reentry trajectory, identified as $\gamma^{*}$, occurs over a very narrow range of reentry angles 


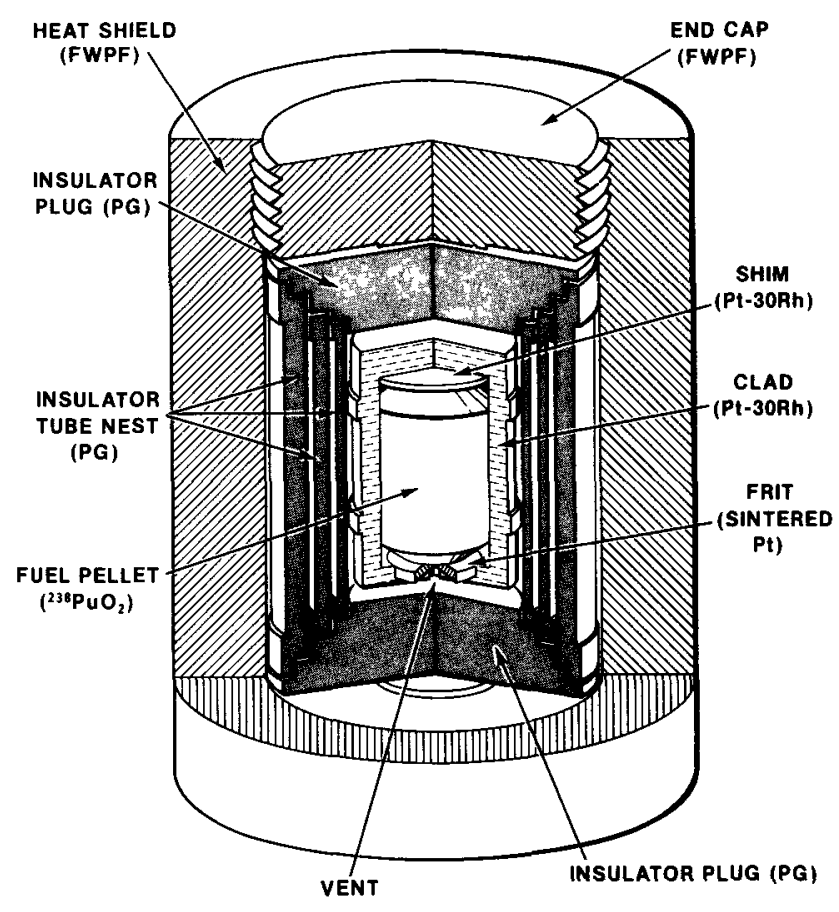

Fig. 1. Light Weight Radioisotope Heater Unit.

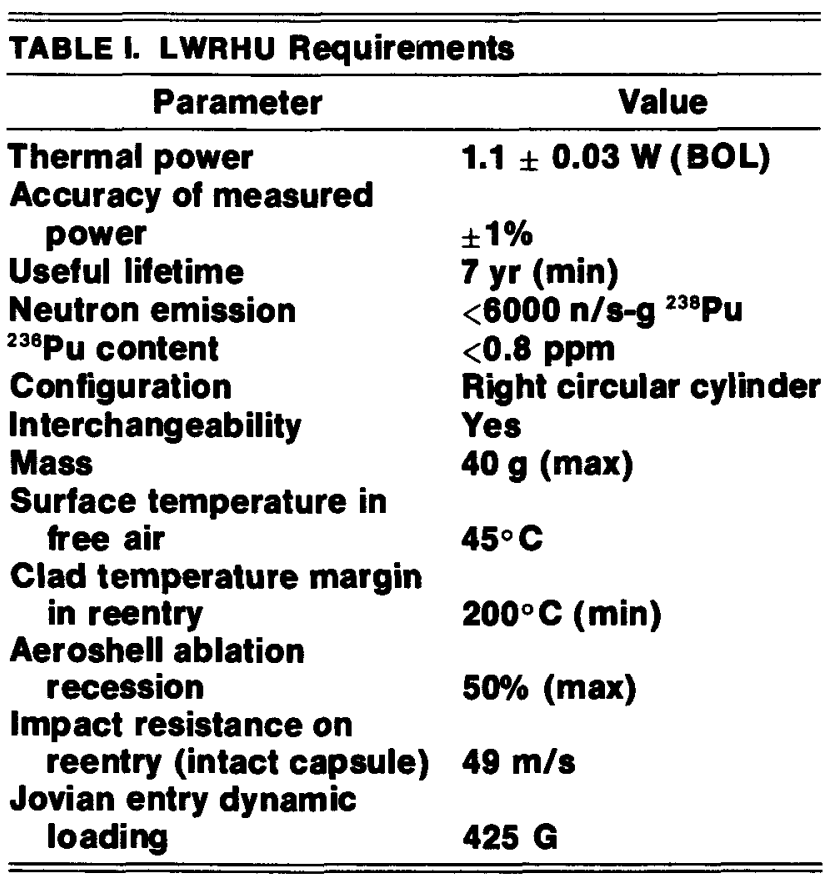

(approximately a few thousandths of a degree) and is a very unlikely reentry mode. However, to be conservative, $\gamma^{*}$ has been used in evaluating reentry performance of the LWRHU design. Because the LWRHU fuel has a relatively low operating temperature, the helium generated by radioisotope decay is mostly stored in the fuel. If the fuel pellet is thermally pulsed, as in a launch abort or earth reentry, this helium must be released in a manner that avoids catastrophic distortion of the capsule by excess pressure. The effect of helium release on the system's thermal performance must also be evaluated. All these critical environments are design challenges.

\section{DESIGN APPROACH}

First, to reduce the unit's mass, the power density of the fuel was increased, and this design change also reduced the volume of the surrounding protective structures for the same degree of protection. Second, to optimize the performance of the protective structures, we changed some materials, refined the design analysis, and abandoned the pressure-vessel concept of containing forever the helium produced by isotope decay.

Previous radioisotope heater units (RHUs) were used on Pioneer 10 and 11, (Ref. 1) Voyager 1 and 2, (Ref. 2) and earlier missions. These MJS/RHUs were fueled with $80 \%$ enriched ${ }^{238} \mathrm{PuO}_{2}$ in shard form and some yttrium-foil chips. Yttrium improves the fuel's compatibility with the tantalum-alloy containment system by gettering oxygen released from the fuel if it is exposed to high temperature. The fuel was triply encapsulated in a Ta-10 $\mathrm{W}$ liner, 0.51 $\mathrm{mm}$ (0.020 in.) thick, a Ta-8 W-2 Hf (T-111 alloy) strength member, $1.02 \mathrm{~mm}$ (0.040 in.) thick, and a Pt-20 Rh clad, $0.51 \mathrm{~mm}$ (0.020 in.) thick, used to eliminate potential reactions between the tantalum base alloy and external environments. Surrounding the metallic capsule was a thermal insulator of pyrolytic graphite (PG) $1.27 \mathrm{~mm}$ (0.050 in.) thick. The outer member (reentry body) was fabricated from polycrystalline graphite, POCO AXF-50, and its minimum thickness was $4.04 \mathrm{~mm}(0.159 \mathrm{in}$.). The MJS/RHU was a cylinder $22.1 \mathrm{~mm}(0.87 \mathrm{in}$.) in diameter and $47.0 \mathrm{~mm}$ (1.85 in.) long. It weighed 57 $g(0.12 \mathrm{lb})$.

For the LWRHU, the fuel's power density was increased significantly by using ${ }^{238} \mathrm{PuO}_{2}$ as a hot-pressed ceramic pellet, a product of technology developed at Los Alamos National Laboratory. The availability of oxide enriched to $83 \%$ also 
improved the power density. Releasing the decay helium through a fine frit of platinum changed the primary encapsulation from a pressure vessel to an impact envelope, and ductility of this envelope became more important than strength. A study of the thermodynamics at the fuel/container interface showed the desirability of using platinum group metals for fuel containment. In the LWRHU the $\mathrm{Pt}-30 \mathrm{Rh}$ alloy containment is one-half the thickness of that in its RHU predecessor, saving both mass and volume. On the other hand, the pyrolytic graphite insulator for the LWRHU is three times the thickness of that in the RHU predecessor. The reentry thermal analysis was refined through many iterations to establish a convincing argument for a substantial safety margin. The aeroshell is about the same thickness as that in the previous RHU, but it takes advantage of newly available technology and the superior properties of FINEWEAVE-PIERCED Fabric (FWPF). The LWRHU is a cylinder $26 \mathrm{~mm}$ (1.02 in.) in diameter and $32 \mathrm{~mm}$ (1.26 in.) long. It weighs $40 \mathrm{~g}(0.09 \mathrm{lb})$. The weights of the piece parts of a production LWRHU are presented in Table II. A set of the LWRHU construction drawings is included in the Appendix.

\section{FUEL}

\section{A. Material}

The radioisotope of choice for long space missions is ${ }^{238} \mathrm{Pu}$ because of its rather long half-life. ( $87.8 \mathrm{yr}$ ), its adequate specific thermal power $(0.42 \mathrm{~W} / \mathrm{g})$, and its tolerable level of penetrating radiation, mostly neutrons from spontaneous fission. The LWRHU fuel material is a mixture of plutonium isotopes in the form of stoichiometric $\mathrm{PuO}_{2}$ containing $83.5 \pm 1 \%{ }^{238} \mathrm{PuO}_{2}$. To achieve the minimum level of penetrating radiation, we must minimize the ${ }^{236} \mathrm{Pu}$ impurity, which has a gamma-emitting daughter, minimize the light-element impurities, which are a source of neutrons from $\alpha \rightarrow n$ reactions, and exchange the ${ }^{17} \mathrm{O}$ and ${ }^{18} \mathrm{O}$ isotopes with ${ }^{18} \mathrm{O}$ to minimize neutrons from alpha particle reaction with the oxygen component of the fuel. Isotope, actinide, and cation analyses for the LWRHU fuel are tabulated in Tables III, IV, and V.

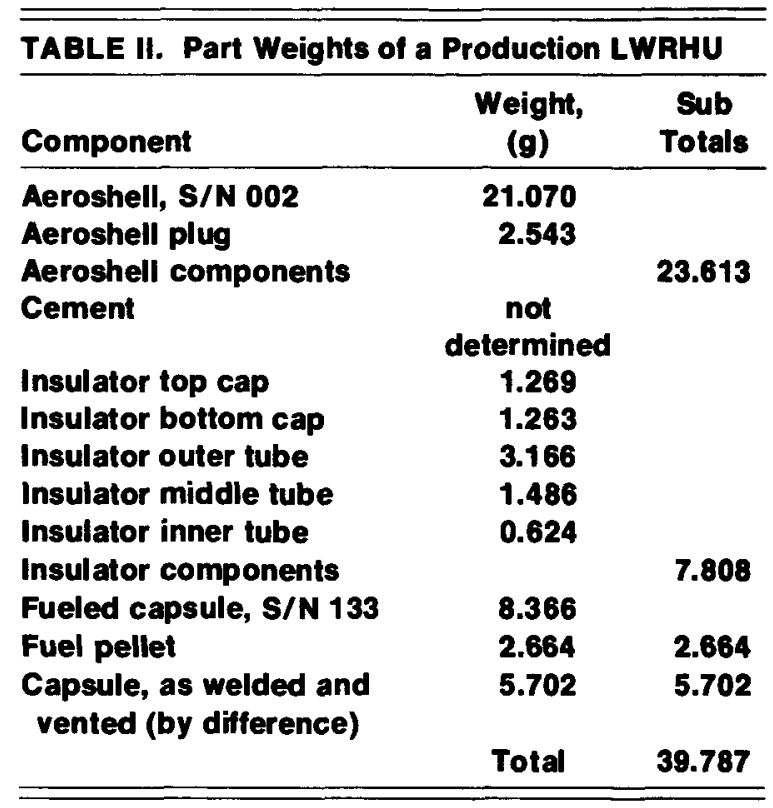

\begin{tabular}{cc}
\hline \hline $\begin{array}{c}\text { TABLE III. Isotopic Composition for LWRHU } \\
\text { Pellets }\end{array}$ \\
\hline Isotope & Wt $\%$ \\
\hline${ }^{238} \mathrm{Pu}$ & 83.62 \\
${ }^{239} \mathrm{Pu}$ & 13.98 \\
${ }^{240} \mathrm{Pu}$ & 1.96 \\
${ }^{241} \mathrm{Pu}$ & 0.41 \\
${ }^{242} \mathrm{Pu}$ & 0.14 \\
\hline \hline
\end{tabular}

\begin{tabular}{|c|c|}
\hline $\begin{array}{c}\text { TABLE IV. Analytical } \\
\text { Pellets }\end{array}$ & Data for LWRHU \\
\hline Species & $\begin{array}{l}\text { ppm by } \\
\text { Weight }\end{array}$ \\
\hline $\begin{array}{l}{ }^{241} \mathrm{Am} \\
{ }^{237} \mathrm{~Np} \\
{ }^{232} \mathrm{Th} \\
{ }^{234} \mathrm{U} \\
{ }^{238} \mathrm{Pu}\end{array}$ & $\begin{array}{c}254^{a} \\
203 \\
232 \\
6191 \\
0.67^{b}\end{array}$ \\
\hline
\end{tabular}

"Specification for actinides is that the sum of ${ }^{241} \mathrm{Am}^{237} \mathrm{~Np},{ }^{232} \mathrm{Th}$, and ${ }^{234} \mathrm{U}$ is $<1 \%$ (10 $000 \mathrm{ppm}$ ) of total plutonium content when back-decayed to date of precipitation.

'Specification for ${ }^{236} \mathrm{Pu}$ is <2 Ppm of total
plutonium. 
TABLE V. Spectrochemical Data for LWRHU Pellets $^{\mathrm{a}}$

\begin{tabular}{cccr}
\hline Species & $\begin{array}{c}\text { Sensitivity } \\
\text { Limits }\end{array}$ & $\begin{array}{c}\text { MHW } \\
\text { Limits }\end{array}$ & $\begin{array}{r}\text { LWRHU } \\
\text { Pellets }\end{array}$ \\
\hline Al & 5 & 150 & 148 \\
B & 1 & 1 & 1 \\
Ca & 3 & 300 & 40 \\
Cd & 10 & 50 & $<10$ \\
Cr & 5 & 250 & 86 \\
Cu & 1 & 100 & 1 \\
Fe & 5 & $800^{b}$ & 203 \\
Mg & 1 & 50 & 175 \\
Mn & 1 & 50 & 9 \\
Mo & 2 & 250 & 4 \\
Na & 2 & 250 & 5 \\
Ni & 5 & 150 & 18 \\
Pb & 5 & 100 & $<5$ \\
Si & 5 & $200^{\circ}$ & 200 \\
Sn & 5 & 50 & 5 \\
Zn & 5 & 50 & 15 \\
\hline
\end{tabular}

appm by weight.

'Limits for Fe and Si are specifications; others are guidelines which are to be reported to the receiving agency when exceeded.

\section{B. Design}

The first step in developing the LWRHU was defining the amount of $\mathrm{PuO}_{2}$ to yield the desired 1.1 $W(t)$ at the beginning of life (BOL). The second step was to define a geometric shape that could be reliably pressed in production quantities and then suitably encapsulated in a minimum volume. In the fuel form development work done at Los Alamos over the past decade, small right circular cylinders with height to diameter ratios of 1.5 were reproducibly manufactured, and hot-pressed and sintered pellets at $86 \%$ theoretical density were handled repeatedly without cracking. With these parameters, the pellet geometry in Fig. 2 was defined. The pellet is a right circular cylinder $6.25 \mathrm{~mm}(0.246 \mathrm{in}$.) in diameter and $9.37 \mathrm{~mm}$ (0.369 in.) high. The chamfers at both ends avoid possible interference problems with the weld underbead in the clad capsule and also reduce the possibility of chipping the pellet edges. The small step at the cylindrical and conical surface intersection results from a requirement of graphite die design for the hot-pressing operation. From a single lot of Savannah River Laboratory Plant feed material, 7 lots of 16 each pellets (a total of 112) were pressed. These

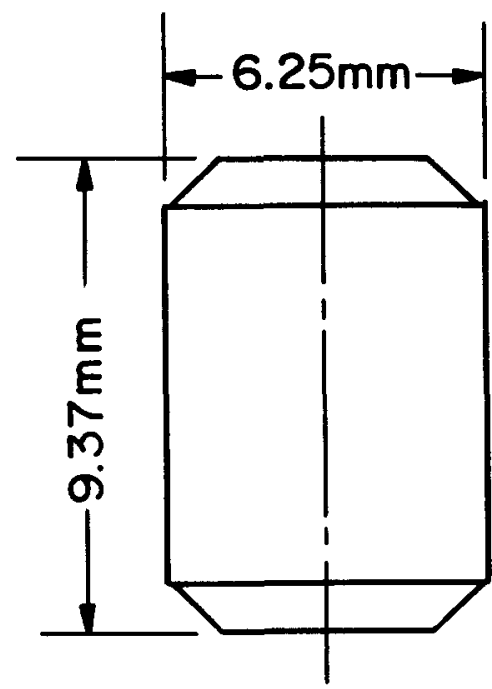

Fig. 2. LWRHU fuel pellet geometry.

pellets weighed $2.664 \pm 0.002 \mathrm{~g}$, were $6.25 \pm 0.03$ $\mathrm{mm}$ in diameter, and $9.37 \pm 0.08 \mathrm{~mm}$ high. The densities were determined to be $87.4 \pm 0.7 \%$ of theoretical. Neutron counting established the neutron emissions at $5190 \pm 103 \mathrm{n} / \mathrm{s} \cdot \mathrm{g}{ }^{238} \mathrm{Pu}$ and calorimetry determined the thermal outputs to be $1.106 \pm 0.005 W(t)$. The activity of the fuel pellet can be calculated to be $33.6 \mathrm{Ci}$.

\section{ENCAPSULATION CLAD}

\section{A. Material}

Thermodynamic studies at Los Alamos over the past decade have established that for compatibility, the best materials for containing $\mathrm{PuO}_{2}$ fuel forms are metals and alloys of the platinum group. The reports of Peterson, Land, and Roof ${ }^{8,4}$ describe the phase equlibria and thermodynamics of the Pu-Pt-Rh system in some detail. For an LWRHU containment capsule, the situation is best summarized in a plot of plutonium pressure over various compounds (Fig. 3). As long as the oxide fuel is not chemically reduced, that is, near the right side of Fig. 3, and as long as the operating temperature is relatively low, chemical reaction at the fuel/clad interface is not predicted nor is it observed. Two further considerations are important in selecting the encapsulation material. It must be ductile at earth reentry impact, and it must have a melting 


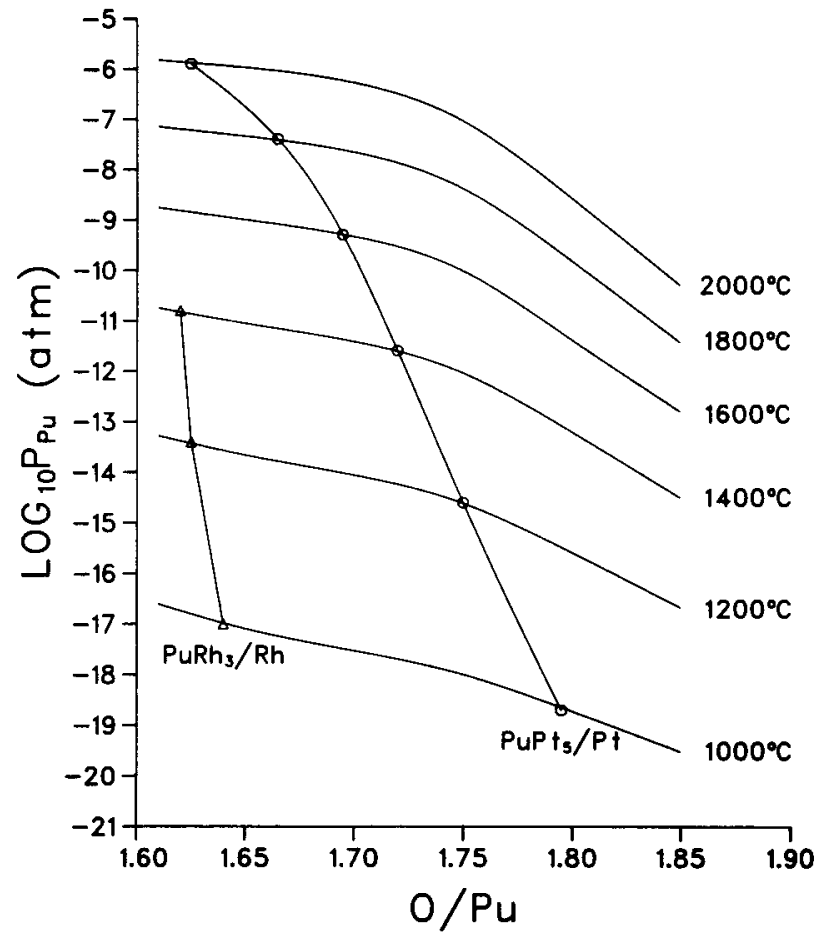

Fig. 3. Plutonium pressures over Pu/Pt-Rh compounds and plutonia as a function of temperature and fuel stoichiometry. ${ }^{4.5}$

point high enough to ensure survival through the reentry thermal pulse. Three candidate materials were screened; Pt-30 Rh, Pt-8 W, both of which are commercial alloys, and Pt-3008 (Pt with $30 \mathrm{Rh}$ and $8 \mathrm{~W}$ ), a new alloy developed at Oak Ridge National Laboratory. Graphite in some form was almost certain to be the material next to the exterior of the encapsulation cladding, so two types of screening test were performed. In the first type, metallographic observations identified the temperature at which the C-Pt alloy eutectic began to form. ${ }^{\circ}$ In the second type, the ductility of alloy samples briefly exposed to graphite at $1700^{\circ} \mathrm{C}\left(3092^{\circ} \mathrm{F}\right)$ was measured at strain rates simulating impact. The results of these tests are summarized in Table VI; Pt-30 Rh was selected for the cladding because of its high ductility and because it is most easily obtained in the desired shapes and sizes, though its use sacrifices some reentry melting point margin. The elongation and strengths of this alloy as a function of temperature, as determined at Oak Ridge, ${ }^{7}$ are illustrated in Figs. 4 and 5.
TABLE VI. Ductility of Cladding Alloys After Reentry Carburization

\begin{tabular}{cccc}
\hline \multicolumn{3}{c}{ Elongation on Tensile Impact" (\%) } \\
\hline & & $\begin{array}{c}\text { Atter 1 min } \\
\text { Graphite Exposure }\end{array}$ \\
\cline { 3 - 4 } Alloy & Unexposed & $1700^{\circ} \mathrm{C}$ & $1750^{\circ} \mathrm{C}$ \\
\hline Pt-30 Rh & 44 & 35 & melt \\
Pt-8 W & 35 & 20 & $<5$ \\
Pt-3008 & $<15$ & -- & -- \\
\hline$(45 \mathrm{~m} / 8)$ & & & \\
\hline \hline
\end{tabular}

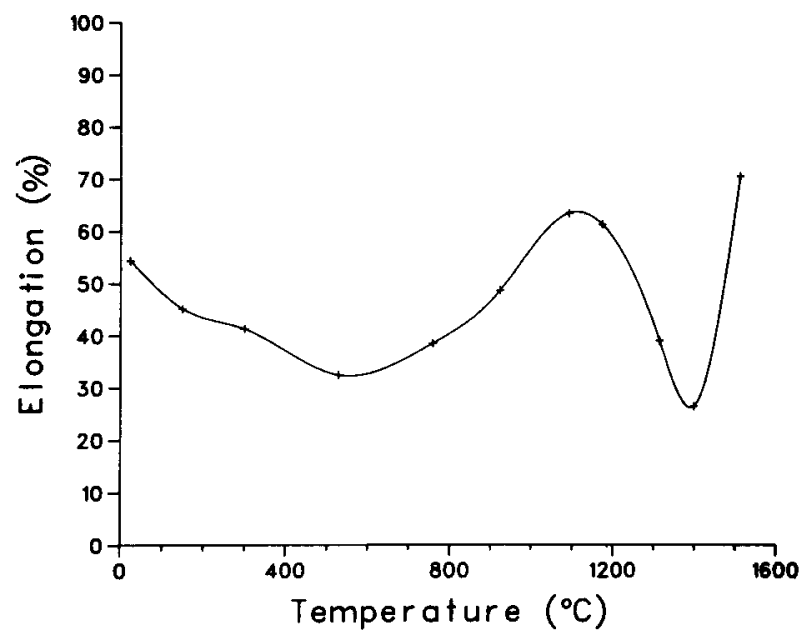

Fig. 4. Elongation of Pt-30 Rh at temperature (Oak Ridge). ${ }^{7}$

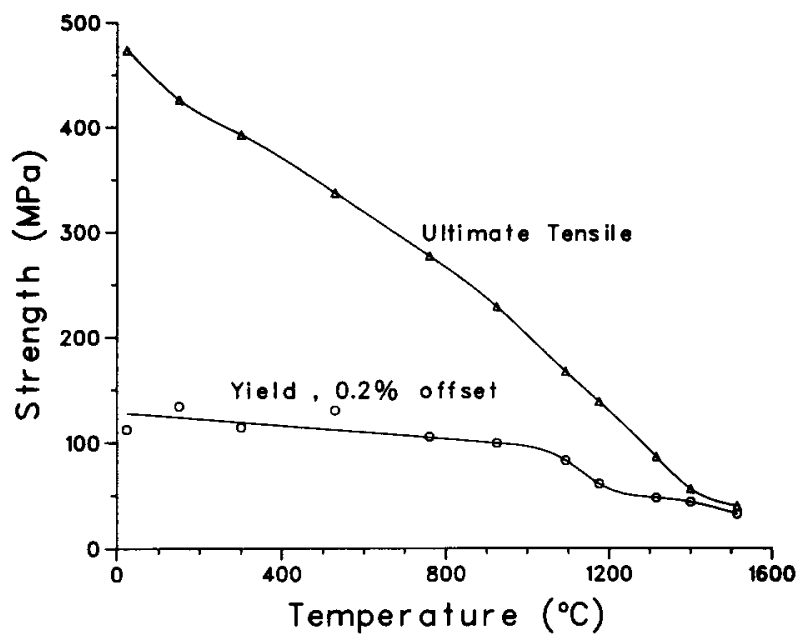

Fig. 5. Strength of Pt-30 Rh at temperature (Oak Ridge).' 


\section{B. Design}

The encapsulation clad geometry is dictated by the cylindrical fuel-pellet dimensions. The clad thickness was established intuitively and arbitrarily at $1 \mathrm{~mm}$ ( 0.04 in.) An exploded view of the fuel pellet and the five clad components (vent end cap, vent frit, clad body, weld shield and closure cap) is shown in Fig. 6. All the alloy components were fabricated from Pt-30 Rh tube, sheet, and foil purchased from a commercial vendor, Matthey Bishop.*

The vent and frit designs were derived from experience with Multi-Hundred-Watt (MHW) heat-source capsules developed at Mound Facility.** The frit is a pressed and sintered disk of pure platinum powder $3.15 \mathrm{~mm}$ in diameter and 0.50 $\mathrm{mm}$ thick. The flow rate of the frit was specified at $0.01-0.03 \mathrm{std} \mathrm{cm}^{3} / \mathrm{s}$ helium at 1 psi differential by scaling down the MHW capsule flow rate in proportion to the relative amounts of fuel in the two types of capsules. Subsequent analysis of the helium release from the LWRHU showed that most of the gas was stored in the fuel at the low operating temperature and released only during a thermal pulse as in reentry. Our experiments demonstrated that the flow rate was adequate to allow this helium to escape without distorting the capsule from excessive pressure build-up. The vent frit is electron-beam welded in a matching recess in the vent end cap (Fig. 7).

The clad body is a piece of $6.60-\mathrm{mm}$ id tubing $12.00 \mathrm{~mm}$ long. After extensive reentry thermal analysis, minimum radial contact with the capsule surface was provided by removing $0.2 \mathrm{~mm}$ from the capsule diameter over much of its length and leaving two 1-mm-wide stand-off rings. The vent end of the body is counterbored to $7.15-\mathrm{mm}$ diam, $1.00 \mathrm{~mm}$ deep. In the subassembly operation, the vent end cap is inserted in the counterbore (frit exposed to the interior), and the subassembly is electron-beam welded in place. An acceptable weld will show a small amount of weld underbead over at least three-quarters of the circumference of the capsule interior. The exterior of the weld bead must also rise $0.1 \mathrm{~mm}$ above the end cap to act as a thermal stand-off.

\footnotetext{
*Matthey Bishop, Inc., 4 Malin Road, Malvern, PA 19335.

**Monsanto Research Corporation, P. O. Box 32, Miamisburg, OH 45342.
}

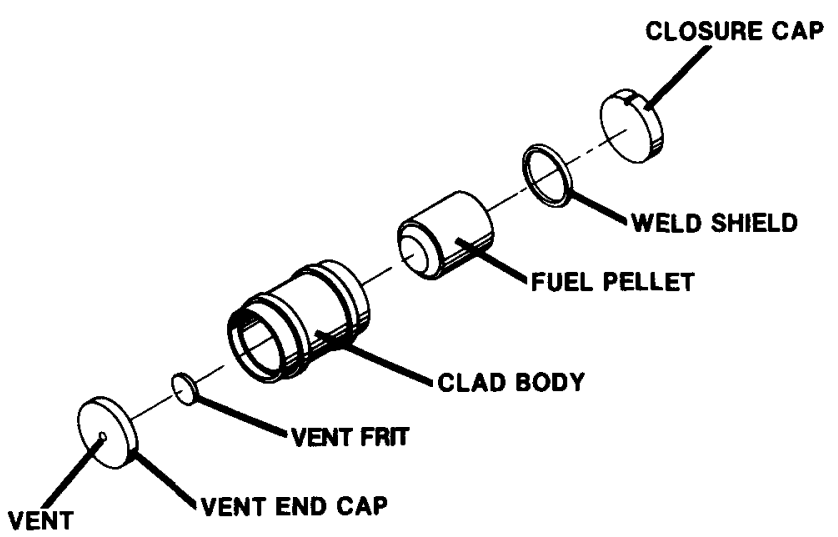

Fig. 6. LWRHU capsule, exploded view.

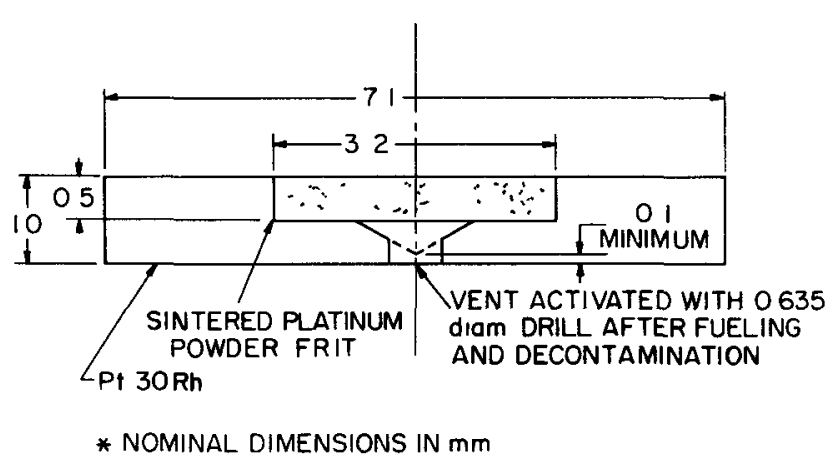

Fig. 7. Cross section of the vent end cap.

The weld shield (also called a shim on some drawings) is a shallow-dished disk deep drawn and blanked from $0.12-\mathrm{mm}$-thick foil. In the capsule fueling process, the shield is placed on top of the fuel pellet and its function is to provide a barrier between the fuel and the closure weld zone.

After fueling, the capsule is sealed by Tungsten Inert Gas (TIG) welding, a choice determined by availability of this equipment in the glove box complex. Thus, the weld-joint design on the closure end differs from that on the vent end. The body on the closure end is counterbored to a depth of 0.50 $\mathrm{mm}$ or one-half the thickness of the closure cap. The closure cap, a disk with a small slot on the circumference for pressure relief of expanding gas, is inserted in the counterbore. The capsule is sealed by TIG welding using parameters that have been developed experimentally by numerous trial 
welds of this specific geometry. The weld bead on the closure end must also be $0.1 \mathrm{~mm}$ high to provide a thermal stand-off.

\section{INSULATOR}

\section{A. Material}

Pyrolytic graphite, a carbonaceous material produced by decomposition of a hydrocarbon gas on a hot surface, is unique among high-temperature materials in that its properties are extremely anisotropic. The thermal conductivity in the A- and B-crystallographic directions ${ }^{8}$ is 50 - 100 times greater than in the $\mathrm{C}$-direction ${ }^{9}$ (Fig. 8). For the LWRHU, this highly directional conductivity is used advantageously during reentry to divert the flow of heat generated at the aeroshell surface around the fuel capsule and to retard the flow of this heat directly into the capsule. Thus, the temperature of the platinum-alloy cladding is maintained safely below its melting temperature. The absolute values of conductivity depend on process variables, particularly deposition temperature, and care must be taken in mathematical modeling to use conductivity values representative of the pyrolytic graphite used. The laminar structure of pyrolytic graphite caused two concerns in its application to the LWRHU: machinability, particularly of stand-off rings, and intact survival in the vibration environment. Experiments demonstrated that tubes with stand-off rings could be machined with a fairly high yield and, once made, they survived vibration testing intact. The laminar structure also limits the wall thickness that can be successfully deposited to form tubes of small diameter. The anisotropy of pyrolytic graphite is also reflected in its thermal expansion. Expansion in the A- and B-directions ${ }^{10}$ is only slightly greater than the expansion of the aeroshell material (FWPF), ${ }^{12}$ but expansion in the $C$-direction ${ }^{10}$ is much greater and must be accommodated in the design (Fig. 9).

\section{B. Design}

The insulator design received the most attention of any component in the LWRHU system. Its performance can best be established by multi-

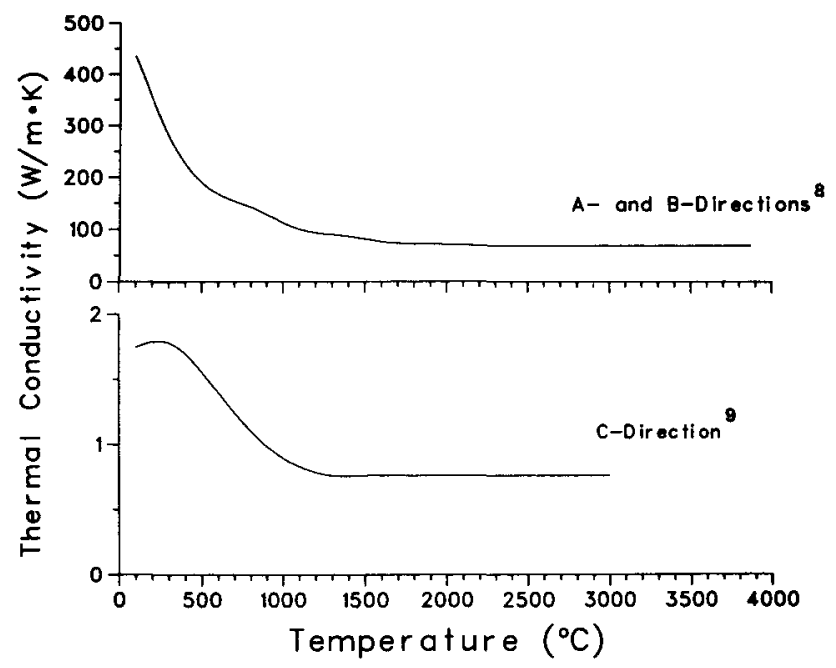

Fig. 8. Thermal conductivities of pyrolitic graphite. $^{8.9}$

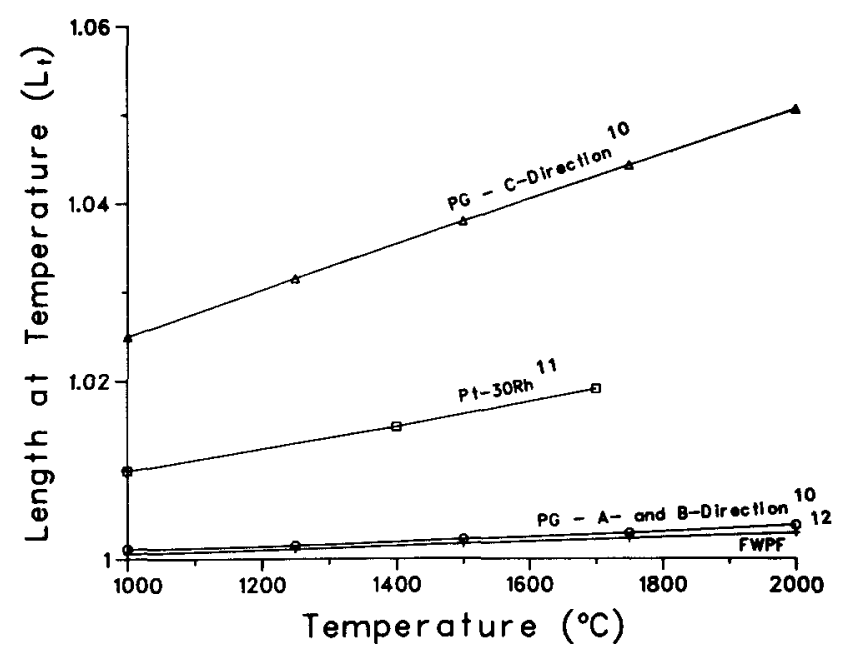

Fig. 9. Thermal expansion of LWRHU materials. ${ }^{10-12}$

dimensional mathematical modeling techniques that cannot be verified by laboratory experiment. As modeling computations became more sophisticated, the predicted maximum clad temperature for reentry rose from a very acceptable $1200^{\circ} \mathrm{C}$ $\left(2192^{\circ} \mathrm{F}\right)$ to temperatures approaching or even exceeding the alloy carbon eutectic at $1700^{\circ} \mathrm{C}$ $\left(3092^{\circ} \mathrm{F}\right)$. The outside envelope dimensions were fixed for NASA designs in the period of low clad temperature predictions and adding insulation 
thickness then became difficult. The problem was eventually resolved by adding thermal stand-offs where possible and eliminating redundant conservatism in the modeling computation.

The insulator consists of the five components shown in Fig. 10 (two equivalent end caps and three nesting tubes). A single tube of appropriate inside diameter and wall thickness cannot be fabricated without delamination. The desired thickness was built from a nest of tubes whose wall thicknesses increased with the tube diameter, that is, inner tube, $0.76-\mathrm{mm}(0.030-$ in. $)$ wall, middle tube, $1.27-\mathrm{mm}(0.050-\mathrm{in}$.$) wall, and outer tube 1.79-\mathrm{mm}$ $(0.70$-in.) wall. The $1.5-\mathrm{mm}(0.60-\mathrm{in}$.) wide stand-off rings were proposed early on, dismissed as impractical to machine and vulnerable to vibration, and finally adopted to improve the insulator's capability after experiments demonstrated that the rings could be made with a reasonable yield and that they would withstand the rather severe vibration levels specified. The end caps are turned from 4.2-mm- (0.165-in.-) thick pyrolytic graphite plate and have four steps to avoid a line-of-sight for radiant heat transfer to the interior. The inner and middle tubes each mate with an end cap step of corresponding diameter; the outer tube is counterbored on its ends, and this tube then mates with the other two steps. Tube length tolerances were established to ensure that the middle tube always determined the overall length of the assembly.

\section{LWRHU AEROSHELL AND INSULATOR ASSEMBLY EXPLODED VIEW}

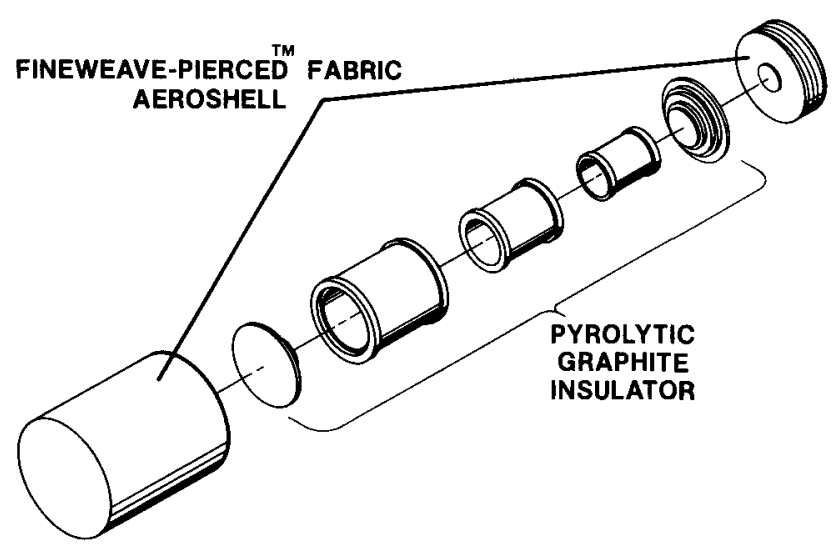

VII. AEROSHELL

\section{A. Material}

The aeroshell is made from FINEWEAVE-PIERCED@ Fabric (FWPF), a proprietary 3-dimensional composite* laid up in an orthogonal array with polyacrylonitrile fibers. This hightechnology graphite was developed for missile applications, and for it there exists a substantial base of engineering data obtained to support a number of other programs. To take advantage of its superior mechanical properties, FWPF was chosen for the LWRHU. This material retains its strength at very high temperatures, has excellent resistance to thermal shock, and unlike bulk graphites, does not fail catastrophically by brittle fracture. Furthermore, FWPF has a high permeability for helium, a feature that precludes degradation of the thermal insulation during reentry.

\section{B. Design}

The aeroshell (Fig. 10) is a thick-walled can with a threaded plug designed to hold the unit together, to provide superior mechanical protection in most environments, and to provide adequate reentry protection. The walls are nominally $4.50 \mathrm{~mm}(0.177$ in.) thick at the cylindrical surface, $4.75 \mathrm{~mm}(0.187$ in.) thick on the end, and the plug is $5.10 \mathrm{~mm}(0.201$ in.) thick. Two bosses, $5.0 \mathrm{~mm}(0.197 \mathrm{in.})$ in diameter and $0.1 \mathrm{~mm}(0.004 \mathrm{in}$.) high on the inner surfaces of the plug and body provide thermal stand-offs to improve thermal resistance during a reentry heat pulse. A test program for the General Purpose Heat Source (GPHS) concluded that the strongest thread form for graphite is the British Standard Whitworth thread and that for three-dimensional graphites, the Z-direction should coincide with the thread-form-axis. These results were applied to the LWRHU closure design. Two 2.0-mm (0.080-in.) diam holes spaced $8 \mathrm{~mm}$ (0.315 in.) apart on a diameter of the plug are used with a spanner to install the plug exactly flush.

*A product of AVCO Systems Division, 201 Lowell St., Wilmington, MA 01887.
Fig. 10. LWRHU aeroshell and insulator, exploded view. 


\section{Cement}

A two-component carbonaceous bonding agent* is used to lock the aeroshell cap in place on final assembly and to fill the spanner holes in the cap. It was used successfully for the same purpose on the earlier RHU design. The two components are a black powder and a molasses-colored liquid. They are mixed in the ratio of 100 parts powder to 35.3 parts (by weight) liquid. After application to the LWRHU, the cement is cured by a thermal cycle of $4 \mathrm{~h}$ at $100^{\circ} \mathrm{C}$ followed by $16 \mathrm{~h}$ at $130^{\circ} \mathrm{C}$.

\section{DEVELOPMENT ANALYSIS}

When the LWRHU design project began, we recognized that the reentry environment could not be totally simulated by laboratory testing and that the project would require support and guidance by a team experienced in computer modeling and analysis. This support was provided by the Applied Physics Laboratory (APL), Laurel, Maryland, throughout the project. In the later stages of the design process, Fairchild Space and Electronics Company, Germantown, Maryland, provided support both independently of and interactively with APL. This report will discuss only the final conclusions from computer modeling of various dynamic problems that might occur in the LWRHU during an inadvertent reentry event. The reader is referred to the APL and Fairchild reports for more detailed treatments of the reentry analysis. ${ }^{13}$

\section{A. Capsule Temperature}

It was crucial to develop a design in which the temperature of the LWRHU alloy clad does not exceed $1700^{\circ} \mathrm{C}\left(3092^{\circ} \mathrm{F}\right)$, the alloy-carbon eutectic temperature, during the worst case reentry thermal pulse. An earth reentry event is quite unlikely, and if it were to occur, its probable mode would be orbital decay. This reentry mode results in a relatively benign thermal pulse and in only a moderate peak clad temperature. Other, more severe, reentry modes are possible. As analysis progressed, APL realized that a reentry trajectory with the classical

-UCAR Cement grade C-34, a proprietary product of Union Carbide, 120 South Riverside Plaza, Chicago, IL 60606 . minimum-gamma flight path angle did not necessarily lead to the highest clad tem perature. A slightly steeper trajectory than $\gamma$-min results in a higher peak clad temperature and this trajectory was christened $\gamma^{*}$. The value of this critical angle is design sensitive. For a particular shape and mass, the worst case reentry angle occurs over a very narrow range (less than a hundredth of a degree). Although the $\gamma^{*}$ reentry is very unlikely, it was used as a conservative evaluation for the LWRHU design. A $200^{\circ} \mathrm{C}\left(360^{\circ} \mathrm{F}\right)$ margin between the peak clad temperature and the $1700^{\circ} \mathrm{C}\left(3092^{\circ} \mathrm{F}\right)$ alloy-carbon eutectic temperature was initially established as the design goal. This margin was achieved after many iterations of the thermal design and refinements of the analytical technique.

To establish with certainty the reentry attitude of the LWRHU was impossible, so calculations were made for both the end-on and side-on stable attitudes. It was possible, however, to establish that the side-on stable attitude resulted in higher peak clad temperatures. The results of the final APL calculation for the reference deign, side-on stable, are illustrated in Fig. 11. The peak clad temperature, calculated to be $1497^{\circ} \mathrm{C}\left(2730^{\circ} \mathrm{F}\right)$ occurs at about $220 \mathrm{~s}$. A similar independent calculation by Fairchild indicates a peak clad temperature of $1450^{\circ} \mathrm{C}\left(2642^{\circ} \mathrm{F}\right)$ at about $260 \mathrm{~s}$. For the end-on

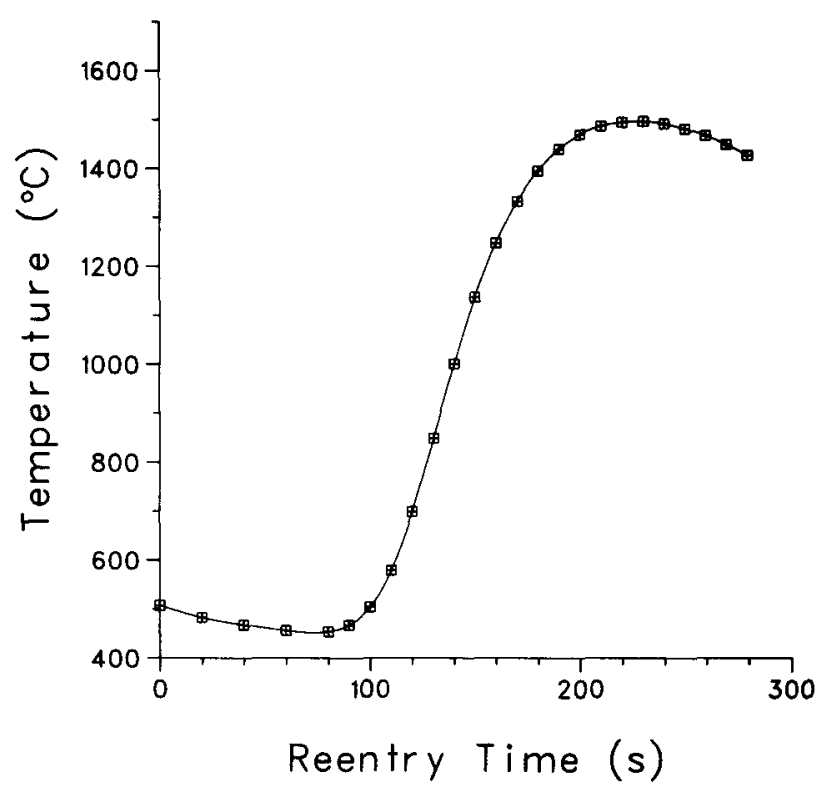

Fig. 11. Prediction of LWRHU clad temperature, side-on stable, three-dimensional modeling for $\gamma^{*}$ reentry. 
stable case, the final APL calculation yielded a peak clad temperature of $1399^{\circ} \mathrm{C}\left(2550^{\circ} \mathrm{F}\right)$ occurring at about $230 \mathrm{~s}$. These calculations all assume that the insulating gaps are in vacuum, and conduction across them is by radiation only.

\section{B. Helium Release}

A basic premise of the LWRHU design was that the decay hellum would be vented through a fine pore metal frit as in the fuel capsules for a Radioisotope Thermoelectric Generator (RTG). This vent is covered until after decontamination of the as-fueled capsule, then opened. The LWRHU, unlike the RTG, operates at a relatively low fuel temperature, at which almost all the decay helium from BOL is stored in the fuel pellet. Upon exposure of the LWRHU to a reentry temperature pulse, this helium is rapidly released. For a time, the possibility that this helium would fill the insulator gaps, degrade their thermal effectiveness, and raise the peak clad temperature beyond an acceptable limit was a serious concern. In a detailed analysis, ${ }^{13,14}$ Fairchild concluded that, because of the very high permeability of the FWPF to helium, the gas leaks from the aeroshell at a rate approximately equal to the release rate. Using the most conservative parameters, the analysis predicts that the gaps become thermally conducting so late in reentry that the clad temperature might rise, at most, a calculated extra $40^{\circ} \mathrm{C}\left(72^{\circ} \mathrm{F}\right)$.

At one stage of design development, very serious consideration was given to permitting the LWRHU vent to self-activate. This concept would preclude increased neutron emission from the possible exchange of fuel oxygen with atmospheric oxygen (the LWRHUs, unlike the RTGs, are handled in air). Limited data indicate that this exchange is very unlikely at the LWRHU fuel temperature. Helium in the clad/fuel interface would improve transfer of reentry heat to the fuel and use the fuel as a heat sink. This option was advocated by the reentry analysts at one point. In the final design, the self-activating vent concept was discarded because it was considered impractical to design and manufacture a system reproducibly self-activating at predictable low pressures. This decision was supported by two tests that pressurized the capsules hydraulically at room temperature. In the first test, the capsule ruptured at the thin portion of the vent recess at $46.9 \mathrm{MPa}$ (6 900 psi). The second capsule did not rupture at $68.9 \mathrm{MPa}$ (10 $000 \mathrm{psi}$ ), the maximum pressure available.

\section{Aeroshell Performance}

The performance of the aeroshell was also evaluated by the reentry analysts at APL. The aeroshell is the LWRHU's heat shield against the reentry thermal and chemical environments and is the load-carrying member for imposed aerodynamic loads and induced thermal stresses. During reentry, a portion of the aeroshell's surface is sacrified through ablation. The design problem is to provide enough material for the worst case ablation, with an arbitrarily defined margin of no more than $50 \%$ recession, and, at the same time to keep the envelope dimensions as small as possible to minimize the penalty of increased weight.

For ablation performance, the most critical trajectories are those with shallow reentry angles. Aeroshell material is removed by three thermochemical regimes and by mechanical ablation of particles. Rate-limited oxidation is most important at surface temperatures below about $2000^{\circ} \mathrm{C}\left(3632^{\circ} \mathrm{F}\right)$. Diffusion-limited oxidation is relatively insensitive to surface temperatures and is important at temperatures below about $2800^{\circ} \mathrm{C}$ $\left(5072^{\circ} \mathrm{F}\right)$. Above $2800^{\circ} \mathrm{C}$, mass loss rates become exponential because of sublimation of the graphite. Recession profiles for the $\gamma^{*}$ trajectory calculated by APL are illustrated in Fig. 12. For the side-on stable attitude, 40 to $45 \%$ recession is predicted; for the end-on stable attitude, 35 to $40 \%$ recession is predicted for this shallow reentry. In both attitudes, the $50 \%$ margin goal is met, and an adequate amount of aeroshell material remains to prevent release of the capsule during the reentry heat pulse.

From mechanical considerations, the most severe reentry condition for the aeroshell occurs on steep angle $\left(\gamma=-90^{\circ}\right)$ reentry at about 7 s. Rapid heating and cooling result in large thermal gradients across the thickness of the aeroshell. These gradients are accompanied by large thermal stresses that could overstress the aeroshell and cause mechanical failure. Early in the LWRHU design effort, thermal stress calculations were 


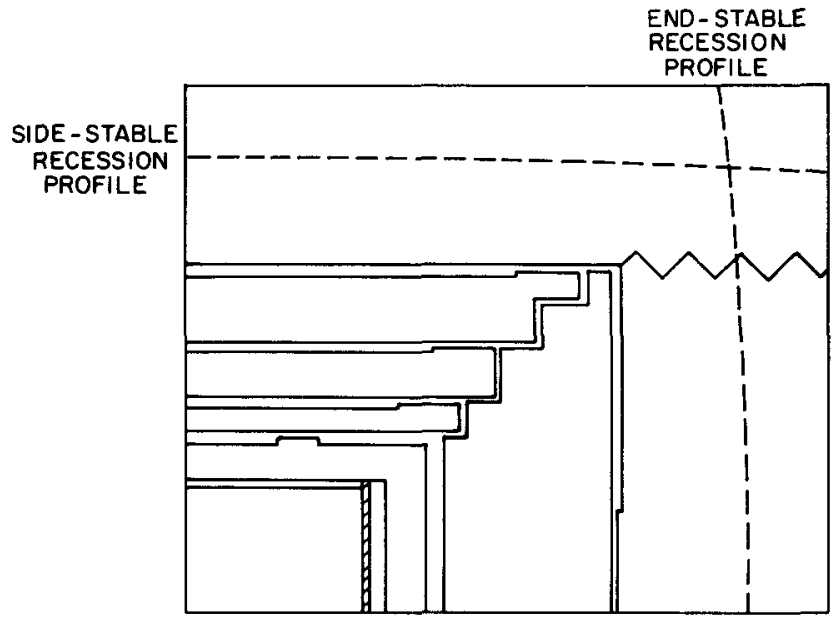

Fig. 12. LWRHU aeroshell recession profiles, nominal heating for the $\gamma^{*}$ trajectory.

made comparing aeroshells of POCO graphite (previously used) and of FWPF carbon-carbon composite used in the LWRHU reference design. The calculated compressive axial stresses on the outer surface of the POCO aeroshell exceed the ultimate strength for that material, and aeroshell failure is predicted under those conditions. Similar calculations for a FWPF aeroshell show a margin of safety of $10 \%$ over ultimate strength. Thermal stress calculations for the final design configuration of the LWRHU in both side-on and end-on reentry attitudes indicate $20 \%$ or greater margins of safety using elastic material properties, except in one stress condition. In that one case, an elastic/plastic analysis was performed, and it resulted in a safety margin of $20 \%$ below ultimate. These calculations project that the FWPF aeroshell provides satisfactory protection for the LWRHU from thermal stress considerations and protection superior to that provided by $P O C O$ graphite.

\section{Impact Conditions}

The terminal velocity of a reentering body is estimated by equating the aerodynamic drag and the weight, a relatively simple calculation. For design purposes it is customary to add $10 \%$ to this velocity for possible impacts at elevations above sea level. In the pertinent aerodynamic flow region for the LWRHU, the effect of surface roughness from ablation is to reduce the drag coefficient below that for a smooth cylinder and thus increase its velocity. The drag coefficient, including the effect of surface roughness, was estimated conservatively to be 0.39 . From the final dimensions and weight of the LWRHU, the sea level terminal velocity was calculated to be $44.5 \mathrm{~m} / \mathrm{s}$ (146 ft/s) and as much as $49.1 \mathrm{~m} / \mathrm{s}(161 \mathrm{ft} / \mathrm{s})$ at higher elevations where the air density is less.

The temperature at impact has been calculated by continuing the $\gamma^{*}$ trajectory analysis through the heat pulse to impact. Air was assumed to permeate through the aeroshell and into the insulator gaps at the end of the heat pulse. At impact, the clad temperature has been calculated to be no greater than $260^{\circ} \mathrm{C}\left(500^{\circ} \mathrm{F}\right)$.

\section{DEVELOPMENT TESTING}

The LWRHU design project was supported by extensive research and development testing. Materials selection for the LWRHU was based, in part, on fundamental studies of fuel-form processing, fuel/container thermodynamics, platinum-alloy/carbon eutectic termperature determinations, and high strain rate response of platinum-alloy samples exposed to graphite for time periods and temperatures considered typical of a reentry heat pulse. The analytical effort was supported by thermal diffusivity measurements on pyrolytic graphite and by measurements of the permeability of FWPF to gas.

Engineering tests were conducted for vibration, helium release, impact, cement volatilization, and G-loading to verify the capability of the materials and configurations of the LWRHU in the environments anticipated for its use.

\section{A. Vibration Tests}

During the early part of the LWRHU design effort, the launch vibration environment was poorly defined. The estimates that existed were very conservative (that is, the LWRHU was expected to survive very high levels of vibration in the random and sinusoidal modes.) The first numerical specification supplied by the Jet Propulsion Laboratory 
(JPL) Pasadena, California, was random mode vibration at $10 \mathrm{G}^{2} / \mathrm{Hz}(100-200 \mathrm{~Hz})$ and $0.4 \mathrm{G}^{2} / \mathrm{Hz}$ $(300-1000 \mathrm{~Hz})$ acceleration spectral density, 2 minutes each for both cylindrical and radial axes. These levels exceed the capability of the largest vibration equipment at Los Alamos. The initial vibration trials were run at one-half this level, that is, 5 and $0.2 \mathrm{G}^{2} / \mathrm{Hz}$, on prototype assemblies similar to the reference design in all respects except that the configuration contained no stand-off rings on the clad or insulator bodies. Capsules loaded with depleted $\mathrm{UO}_{2}$ fuel simulant were used in this and all subsequent vibration tests. Minimal weight losses were experienced by the pyrolytic graphite parts, the most vulnerable components. Carbon-Bonded Carbon Fiber (CBCF), an attractive low-density and low-thermal conductivity graphite material, was also investigated as an insulator at this time. However, vibration testing of prototype using only CBCF as insulation at one-half and one-fourth of the original vibration specification resulted in very serious insulator weight and shape losses.

As the design effort progressed, JPL and NASA's Ames Research Center (ARC), Moffett Field, California, refined their estimates of the random and sinusoidal mode vibration environments. The enveloped specification for the GLL Orbiter (JPL) and the GLL Probe (ARC) are illustrated in two accompanying figures. Figure 13 shows a plot of the acceleration spectral density vs frequency (random mode), and Fig. 14 shows a plot of the peak acceleration vs frequency (sinusoidal mode). In both cases, two levels are shown, a flight acceptance level, which is the vibration level anticipated in actual use, and the type acceptance level, which is a $50 \%$ overtest to qualify the design. A very few LWRHUs are mounted on an orbiter antenna boom where high sinusoidal levels are expected. At one time building special units for this location was considered. Note that the final random mode specification in the low-frequency range has dropped from the original of 10 to $1.5 \mathrm{G}_{2} / \mathrm{Hz}$, a factor of 6 . The 49 Gs peak acceleration for the antenna location still exceeds the capacity of the equipment at Los Alamos, so two series of tests were run at JPL.

The first test series run at JPL provided a comparative evaluation of the all-pyrolytic graphite design and a composite design in which two CBCF materials replaced the outer insulator tube in a non-load bearing configuration. The two CBCF

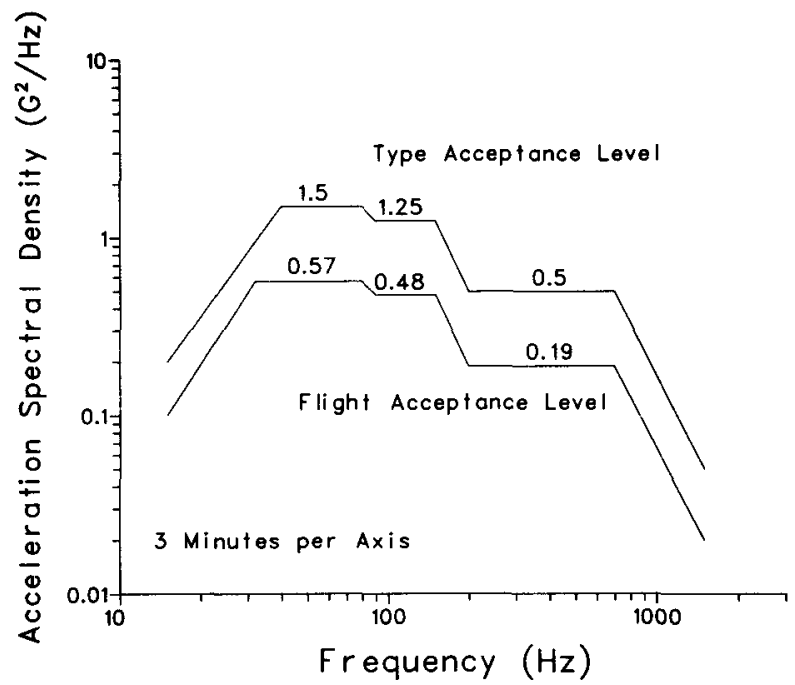

Fig. 13. Random mode vibration environment for the LWRHU.

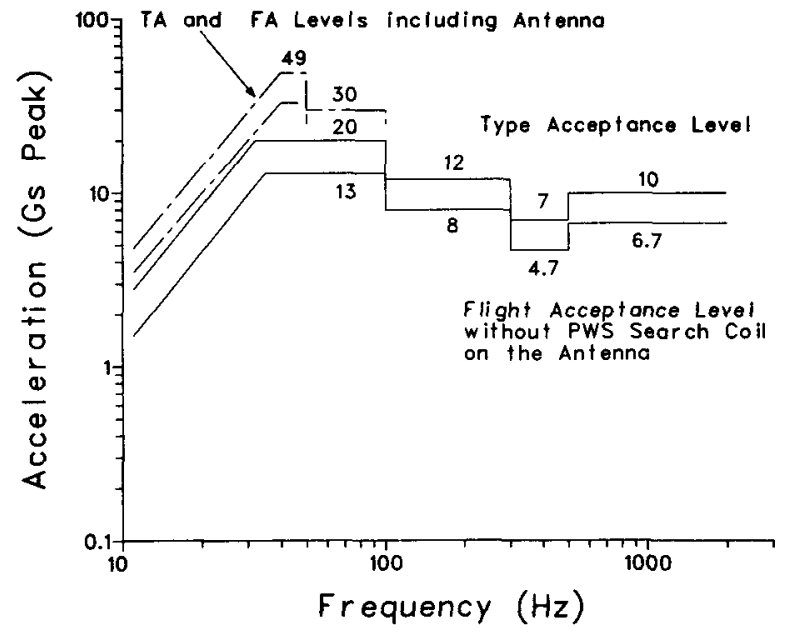

Fig. 14. Sinusoidal mode vibration environment for the LWRHU.

materials used were characterized by their densities at 0.2 and $0.3 \mathrm{~g} / \mathrm{cm}^{3}$. A set of the three different prototypes was run simultaneously in the random mode, initally at the flight acceptance level and then at the type acceptance level. Outer tube degradation was monitored by weighing that component on an analytical balance before and after each test level to determine weight loss. A similar set of the three different prototypes was run simultaneously in the sinusoidal mode at three levels: flight acceptance, type acceptance, and type acceptance 
with antenna. Insulator degradation was again monitored by measuring weight loss at each level. Weight losses and dimensional changes were almost undetectable for the pyrolytic graphite outer tube after each and all levels. The cumulative total weight loss for the 0.3 CBCF outer tube after all sinusoidal levels was $4 \mathrm{mg}$ or $0.85 \%$. The cumulative total weight loss for the $0.2 \mathrm{CBCF}$ outer tube was $8 \mathrm{mg}$ or $2.6 \%$. Some graphite powder was visible when the units with CBCF were disassembled. In this configuration, CBCF was evaluated as marginally acceptable from the vibration standpoint.

The second test series run at JPL evaluated two configurations of pyrolytic graphite designed to ensure gaps between the insulator tubes and included an insulator end cap design with four approximately equal steps. In one concept, positive gapping between the tubes is achieved by tight tolerances on the tube outside diameter (machined without rings), and the tube inside diameters are supported on the end cap steps. In the other gapping concept, the outside diameters of the three tubes are reduced $0.2 \mathrm{~mm}$ by machining except for a distance of $1.5 \mathrm{~mm}$ at each end. This configuration gives a $0.1 \mathrm{~mm}$-high stand-off ring to ensure positive gapping over most of the tube interfaces. Each set of three prototypes was vibrated sequentially, axially, then radially in the random environment. One set of units was vibrated simultaneously at flight acceptance levels, the other set at the more severe type acceptance levels. All units survived the tests acceptably, although more wear and weight loss were evident in the units vibrated at the type acceptance level. The individual part weights and weight losses from vibration testing are summarized in Table VII. In all cases, the stand-off rings were still quite visible and functional after exposure to the higher level vibration environment.

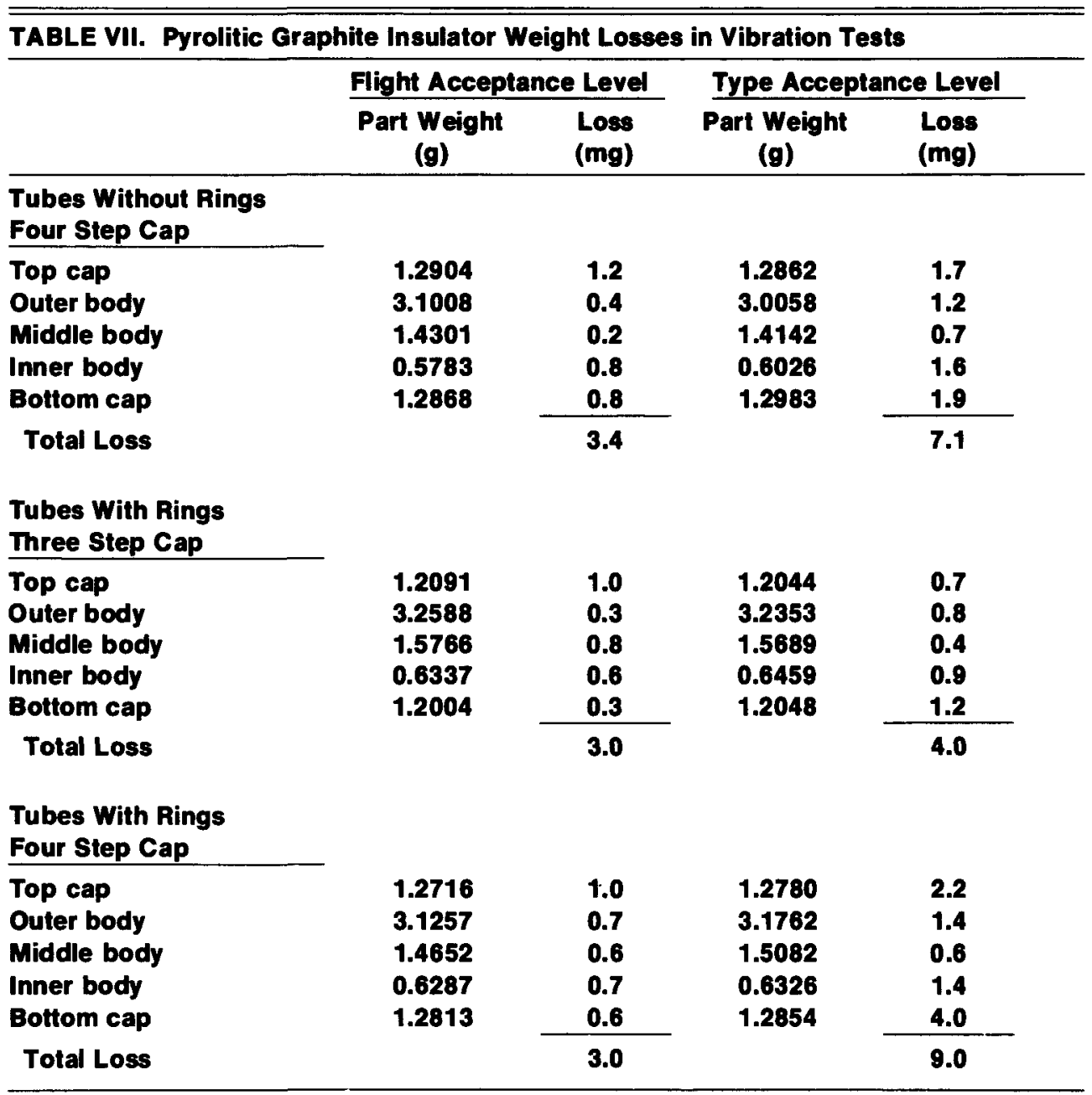


The insulator design with stand-off rings and a four-step end cap was selected for the final reference design. For manufacturing reasons, the stand-off rings were favored over the design requiring tighter tolerances. The four-step end cap takes better advantage of the directional conductivity of pyrolytic graphite.

\section{B. Helium Release Tests}

The vented LWRHU is a new application of ${ }^{238} \mathrm{PuO}_{2}$ fuel and the decay helium presents a unique problem. Because of its low power, the normal fuel temperature of the LWRHU is relatively low, and most of the helium is stored in the fuel from BOL. If the fuel is heated to high temperature, as in a reentry pulse, this helium is released. The release rate depends, in part, upon the reentry temperature ramp. Helium release poses two important design problems. If the vent flow rate is inadequate, the fuel capsule will be pressurized, and deformation or even rupture of the capsule is possible. If helium is released early in the reentry pulse, it could degrade the thermal insulation system by filling the insulator gaps, and this perturbation could cause an unacceptable rise in the peak clad temperature. Helium release from plutonia has been investigated for $30 \mathrm{yr}$, but, until very recently, the plutonia fuel forms studied were either powder or microspheres. Helium diffusion data from these earlier measurements were used to estimate the helium release rates and initiation times during worst case LWRHU reentry events. However, there are uncertainties in the data and in the analytical model. A series of engineering tests provided the best evaluation of fuel and capsule performance during a simulated reentry pulse.

These engineering tests ${ }^{15}$ were conducted in a glove box and inside a Centorr tungsten-mesh resistance furnace operating in vacuum. The furnace power input was controlled manually. A time-power setting program to produce the desired temperature ramp was developed using a fueled capsule dedicated to this purpose. The capsule temperature was recorded from a Pt-10 Rh thermocouple in contact with the capsule, and this temperature measurement system was checked with an optical pyrometer. A helium leak detector with recorder was connected to the furnace va- cuum system. Before each test, this helium detection system was calibrated by introducing tank helium into the vacuum system through a Teledyne flow meter. The vents in two capsules were activated by drilling $0.6-\mathrm{mm}$-diam holes outside the vent frits before fueling these capsules. We were fortunate to have suitable fuel pellets about $7.5 \mathrm{yr}$ old from earlier fuel development work. Pairs of these pellets were very similar in mass and size to the LWRHU fuel pellet, and pairs of these overage pellets were used as fuel in these tests. The dimensions of the fueled capsules were measured carefully with a metric micrometer just before loading them into the furnace for a test. The temperature ramp used in these tests was the most severe ramp predicted by the analysts at the time the tests were conducted. This ramp was predicted by Fairchild and rose rapidly to $\sim 1600^{\circ} \mathrm{C}\left(2912^{\circ} \mathrm{F}\right)$ in $90 \mathrm{~s}$. It was an overtest in comparison to the $\sim 1500^{\circ} \mathrm{C}\left(2732^{\circ} \mathrm{F}\right)$ predicted later by APL.

The results of these helium release tests are summarized in Fig. 15 and Table VIII. The figure presents the data obtained from capsule 027, the second of the two tests. Clearly, the experimental temperature ramp provided a severe test. Almost all the helium is released before the clad reaches the peak temperature. As indicated in the table, no deformation of the capsule could be detected by posttest micrometer measurements of the capsule. The vent system is adequate to release the helium with some safety margin. Helium is released to the interior of the aeroshell relatively late in the reentry temperature ramp and at a time and rate very dependent upon this ramp. The permeability of the aeroshell to the released helium and the calculation of its ability to conduct helium from the LWRHU at a rate equal to or greater than the helium release rate alleviated earlier concerns that the released helium would seriously impair the insulation system. A post-mortem of the test capsules showed that the fuel remained intact through the reentry thermal pulse.

\section{Impact Test}

Because many postulated accident paths for ${ }^{238} \mathrm{PuO}_{2}$ heat sources include terrestrial impact, demonstrating adequate isotope fuel containment 


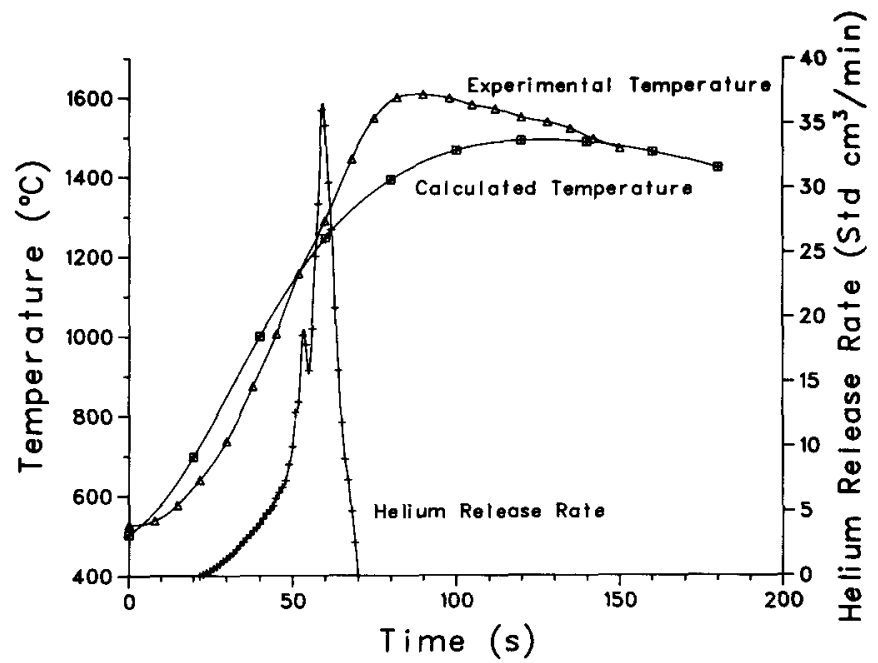

\begin{tabular}{|c|c|c|}
\hline $\begin{array}{r}\text { TABLE VIII. Data for Reentry Te } \\
\text { of Helium Release }\end{array}$ & $\begin{array}{l}\text { lure } \\
\text { VRH }\end{array}$ & \\
\hline Capsule identification & 004 & 027 \\
\hline Vent flow rate, Std $\mathrm{cm}^{3} / \mathrm{s} @ 1$ psi & 0.019 & 0.010 \\
\hline Fuel age, yr & 7.5 & 7.75 \\
\hline Helium inventory, std $\mathrm{cm}^{3}$ & 8.2 & 8.5 \\
\hline $\begin{array}{l}\text { Capsule swelling } \\
\text { Incipient helium at clad }\end{array}$ & none & none \\
\hline temperature, ${ }^{\circ} \mathbf{C}$ & 850 & 910 \\
\hline $\begin{array}{l}\text { Maximum helium release at } \\
\text { clad temperature, }{ }^{\circ} \mathbf{C}\end{array}$ & 1270 & 1290 \\
\hline Helium inventory, & & \\
\hline $\begin{array}{l}\text { percentage released } \\
\text { Integrity of fuel }\end{array}$ & $\begin{array}{l}95 \\
\text { yes }\end{array}$ & $\begin{array}{l}99 \\
\text { yes }\end{array}$ \\
\hline
\end{tabular}

for heat source designs is necessary. Over a decade, Los Alamos has developed equipment and a technology to impact fuel and its containment to velocities as high as $300 \mathrm{~m} / \mathrm{s}$ in a manner that provides safe secondary containment of the ${ }^{238} \mathrm{Pu}$ fuel. Previously, impact tests using dummy heat sources loaded with simulant fuel were conducted. The test results were then extrapolated to real heat sources with considerable uncertainty because of unknown and/or poorly controlled properties of the fuel simulant.

Los Alamos has two gas guns designed specifically for impacting ${ }^{238} \mathrm{Pu}$ fuel assemblies, a gun with a $50.8-\mathrm{mm}$ (2-in.) bore and a larger gun with a 178-mm (7-in.) bore. Impact chambers are coupled directly to the gun barrels. Fuel assemblies are impacted within a catch tube. When the projectile enters the catch tube, a tapered portion of the
Fig. 15. Helium release from $L W R H U$ capsule $S / N$ $027 .{ }^{15}$ projectile jams into a mating taper in the catch tube to provide effective secondary containment of the radioisotope fuels.

Impact tests on the LWRHU began with the first fueled development capsule. Visually and radiographically, it appeared satisfactory; so it was impacted side-on, without graphite, at $48 \mathrm{~m} / \mathrm{s}$. We expected modest plastic deformation and it occurred. The results were quite encouraging and within a few weeks, more impact tests were done, first end-on, then at $45^{\circ}$ at a velocity of $48 \mathrm{~m} / \mathrm{s}$, and then side-on at $68,88,105$, and $128 \mathrm{~m} / \mathrm{s}$. From other impact tests, we considered the side-on impact geometry the most vulnerable. In this series of tests, the amount of capsule deformation increased with the velocity, but no ruptures of the Pt-30 Rh clad were observed. An upper limit of $128 \mathrm{~m} / \mathrm{s}$, derived from a National Regulatory Commission containment specification for air shipment of plutonium, $^{18}$ was considered reasonable for the tests. Significant protection from capsule deformation can be expected from the graphite parts of the LWRHU. An impact test was run at $105 \mathrm{~m} / \mathrm{s}$ with the capsule surrounded by graphite parts. In this test, the aeroshell was machined to simulate the results of reentry ablation. After we decided to activate the vent, a vented capsule including graphite was tested at $48 \mathrm{~m} / \mathrm{s}$.

Impact test results (Fig. 16) show end-on views of capsules after various tests. Figure 16 (b) at 128 $\mathrm{m} / \mathrm{s}$ should be compared with Fig. 16 (a) at $48 \mathrm{~m} / \mathrm{s}$, both impacted bare. Figure 16 (c) impacted bare at $105 \mathrm{~m} / \mathrm{s}$ should be compared with Fig. 16 (d) 


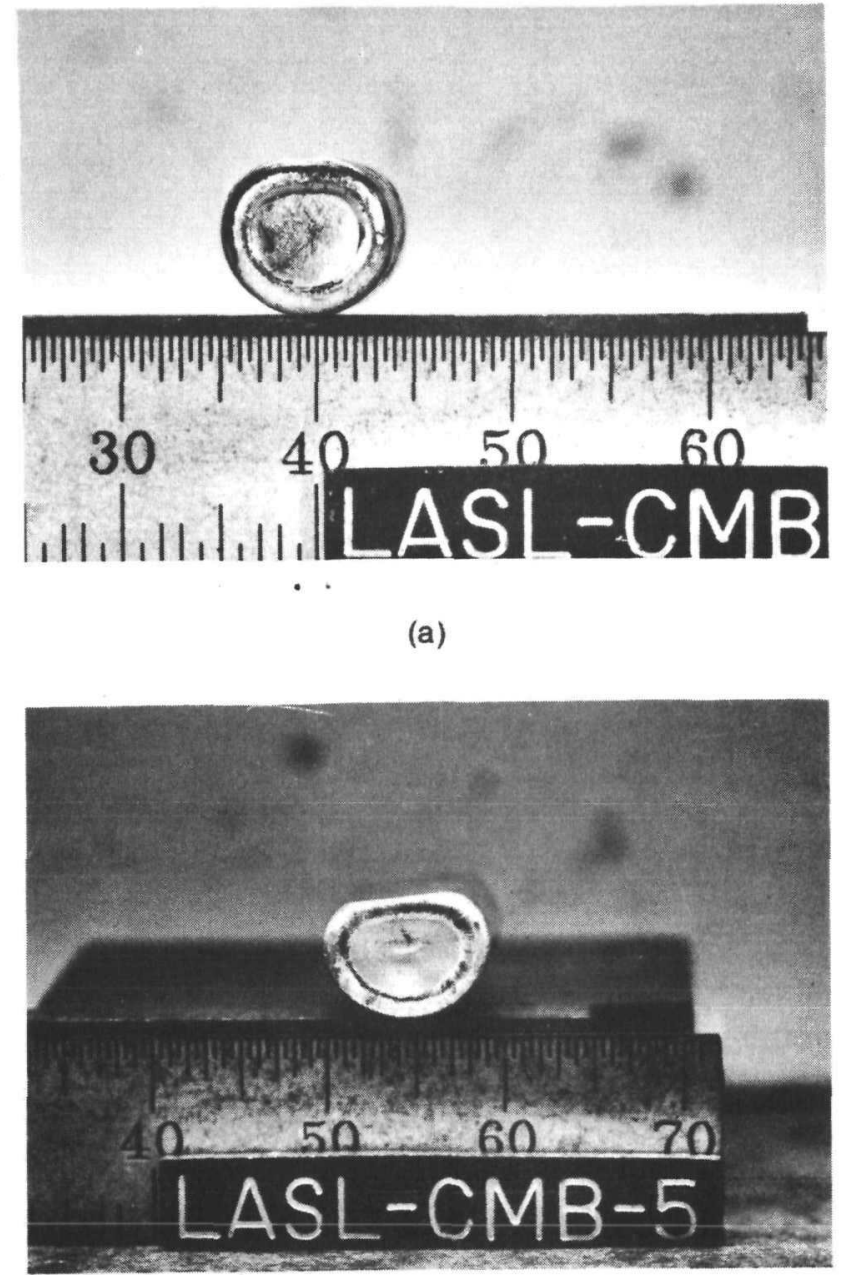

(c)

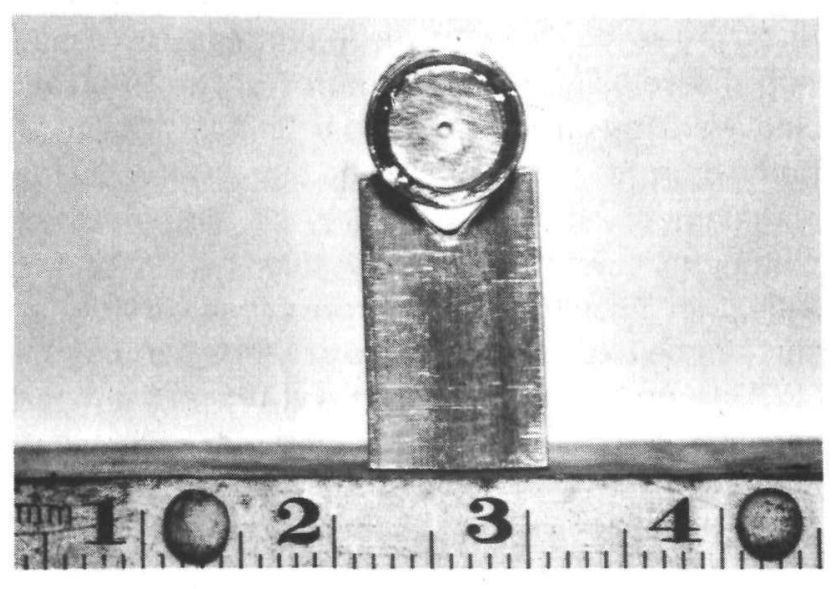

(e)

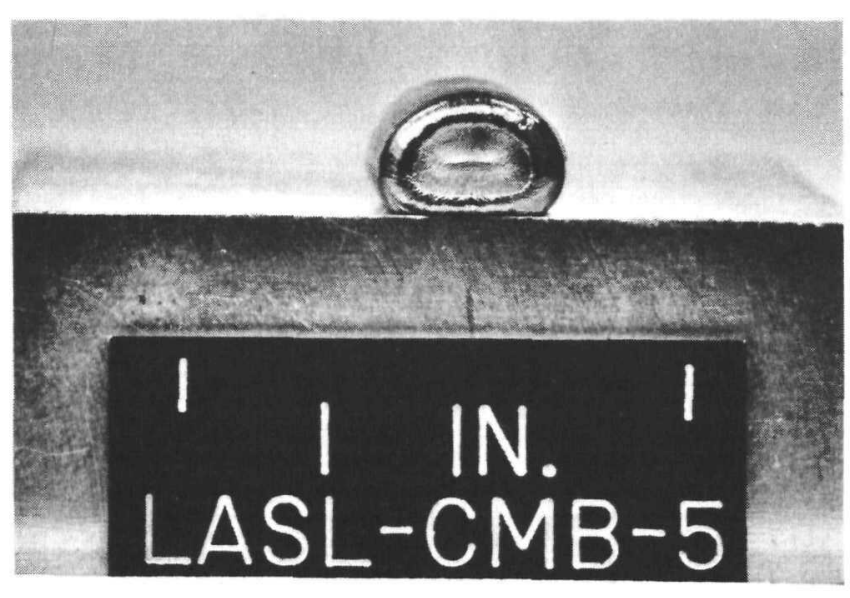

(b)

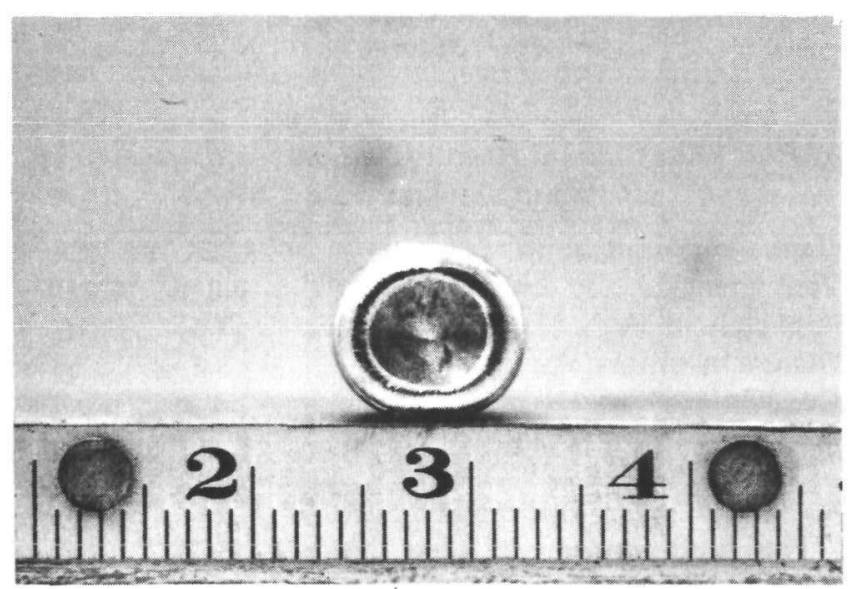

(d)

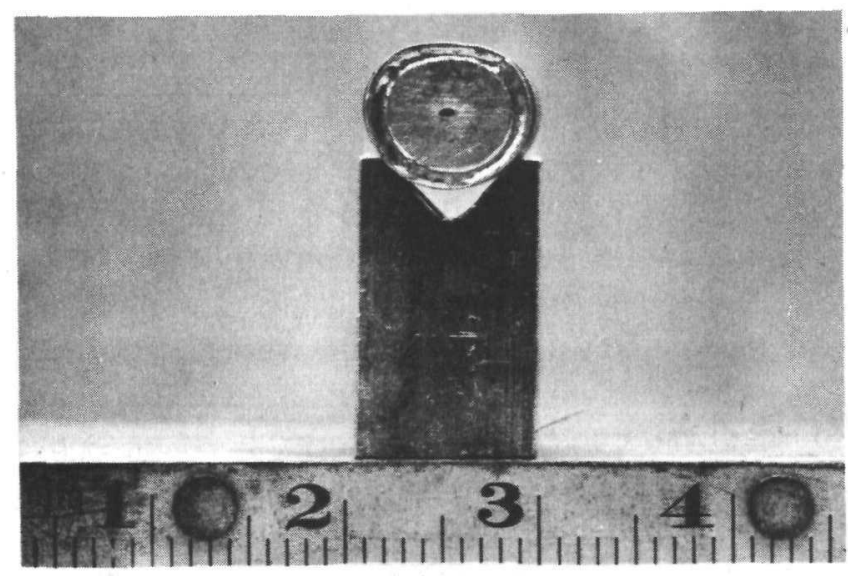

(f)

Fig. 16. LWRHU impact test capsules; (a) $48 \mathrm{~m} / \mathrm{s}$, bare; (b) $128 \mathrm{~m} / \mathrm{s}$, bare; (c) $105 \mathrm{~m} / \mathrm{s}$, bare; (d) $105 \mathrm{~m} / \mathrm{s}$, with graphite; (e) vented, before impact; (f) vented, $48 \mathrm{~m} / \mathrm{s}$, with graphite. 
impacted with graphite also at $105 \mathrm{~m} / \mathrm{s}$. And finally Fig. 16 (e), capsule 027 after the helium release test but before impact, shoud be compared to Fig. 16 (f), the same capsule after impacting with graphite protection at $48 \mathrm{~m} / \mathrm{s}$. These photographs and tests demonstrate that the ductile Pt-30 Rh capsule contains the fuel very well under impact.

\section{G Loading Test}

The engineers for the GLL Probe requested that an LWRHU with simulant fuel be tested to a loading of $425 \mathrm{G}$ to simulate the loading anticipated when the Probe descends into the Jovian atmosphere. The mounting hardware (a support base, two straps, and four screw fasteners) was supplied by a Probe contractor, the Reentry Systems Division of General Electric Company, Philadelphia, Pennsylvania. The LWRHU was mounted on a 4 in. by 4 in. centrifuge adaptor plate made of aluminum alloy (Fig. 17). The bottom surface of the support base is spherical to match the large spherical radius of the aft cover of the Probe. The support base was mated to the flat adaptor plate by allowing epoxy resin to harden in the interface with the socket head screws loosely tightened and later tightening these fasteners to specification.

The actual G-load testing was performed by the Environmental Testing Department at Sandia National Laboratories, Albuquerque, New Mexico.
The LWRHU test assembly was mounted in a centrifuge, model 1079, built by Genisco Technology Corporation. The G-loading was perpendicular to the cylindrical axis of the LWRHU and in the direction to pull the unit away from the mounting fasteners. In the test run, the loading was quickly brought to $425 \mathrm{G}$ where it remained for $15 \mathrm{~s}$. The loading was above $300 \mathrm{G}$ for $30 \mathrm{~s}$.

The LWRHU and mounting hardware survived the 425-G-loading without incident. After the test, the graphite components were disassembled and inspected visually with care. Absolutely no evidence of change was observed.

\section{Acknowlegments}

The development of the LWRHU design was truly a multidisciplinary effort. At Los Alamos considerable assistance in heat source design was contributed by S. E. Bronisz, in alloy selection by S. S. Hecker, and in graphite selection by R. W. Zocher. The fuel form was developed under the direction of R. A. Kent, who also supervised the fueling of the development and test units. Welding techniques were developed by E. D. Brandon and $\mathrm{H}$. Casey. The helium release studies were conducted by R. N. R. Mulford, D. E. Peterson, and J. S. Starzynksi. Impact testing was done under the direction of C. E. Frantz and vibration testing under the direction of N. K. Kernodle. The extensive

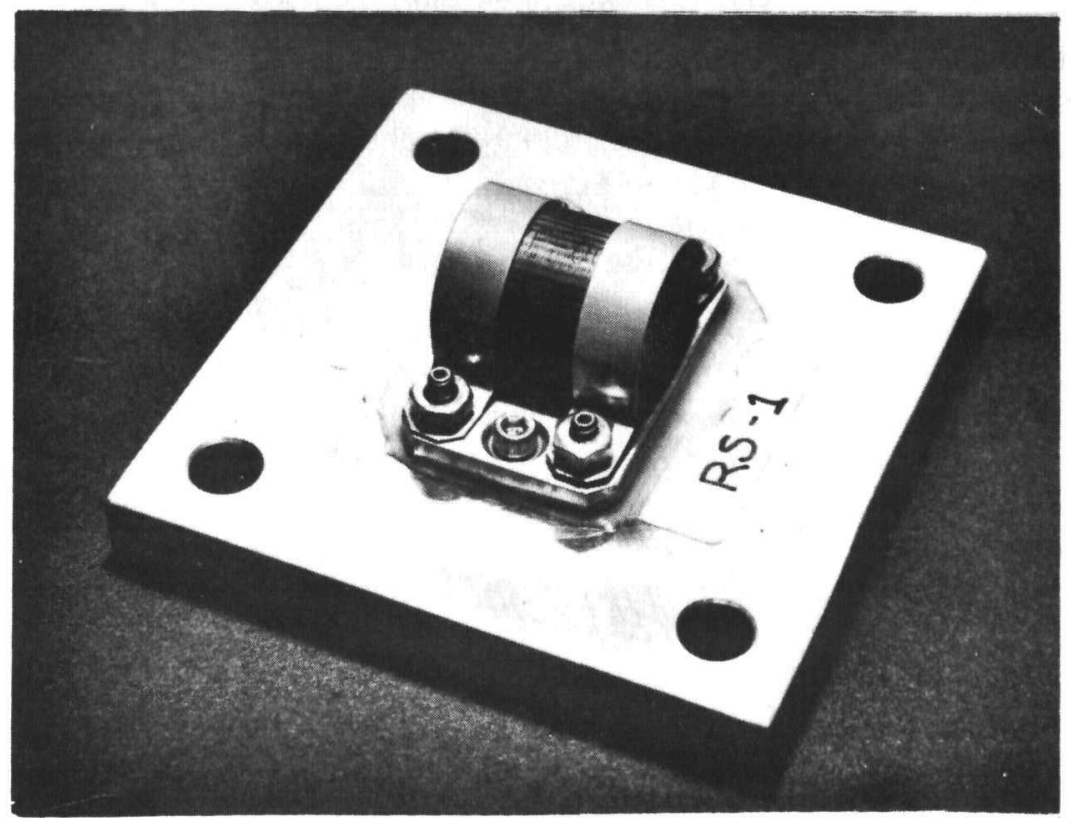

Fig. 17. LWRHU G-load test assembly. 
metallographic effort was conducted by C. C. Land. Precision alloy machining of prototypes was done under the direction of $E$. Kenner and precision graphite machining was done under the direction of C. H. Baca.

Contributions from other organizations are also acknowledged. J. C. Hagan coordinated the efforts at the Applied Physics Laboratory, C. Alexander at Battelle Columbus Laboratory, A. Schock at Fairchild Space and Electronics, R. G. Ivanoff at the Jet Propulsion Laboratory, and E. W. Johnson at the Mound Facility. G. L. Bennett represented the Department of Energy's Office of Special Projects in a very active role.

\section{REFERENCES}

1. "Safety Analysis Summary Report for the Pioneer Radioisotope Heater Unit," TRW System Group report PFG273-324 (February 1971).

2. Safety Analysis Summary Report for the MJS Radioisotope Heater Unit," Mound Facility report MLM-ML-76-48-0003 (August 1976).

3. C. C. Land, D. E. Peterson, and R. B. Roof, "Phase Investigations of the Pu-Pt, Pu-Rh, and Pu-Pt-Rh Systems," J. Nuc. Mater. 75, 262-273 (1978).

4. D. E. Peterson, C. C. Land, and R. B. Roof, "Phase Equilibria, Thermodynamics, and Crystal Structures for the Pu-Pt-Rh System," Los Alamos Scientific Laboratory report LA-6968 (December 1977).

5. R. J. Ackerman, R. L. Faircloth, and M. H. Rand, "A Thermodynamic Study of the Vaporization Behavior of the Substoichoimetric Plutonium Dioxide Phase," J. Phys. Chem. 70, 3698-3706 (1966).

6. J. R. Keiser, "Development of Pt-Base Alloys," in Technical Highlights of Isotopic Power Materials at Oak Ridge National Laboratory for November 1979, A. C. Schaffhauser, Comp., Oak Ridge National Laboratory report ORNL CF-80/34 (February 1980), p. 11.
7. J. R. Keiser, "Characteristics of Tensile Properties of Pt-30 Rh (wt\%)" and "Mechanical Properties of Pt-30 Rh," in Technical Highlights of Space and Terrestrial Systems Programs at Oak Ridge National Laboratory for March 1980 and May 1980. A. C. Schaffhauser, Comp. Oak Ridge National Laboratory reports CF-80/90 and CF-80/258, (May and August 1980) p. 23 and p. 9 , respectively.

8. SNAP 19, Viking Final Safety Analysis Review, Teledyne Energy Systems Document ESD 3069-1, Vol. 1 (August 1974), p. A-6.

9. R. N. R. Mulford, Office Memorandum, Group CMB-5, Los Alamos National Laboratory, "Thermal Conductivity of Pyrolitic Graphite," September 24, 1979.

10. NERVA Program Data Book (May 1, 1966).

11. Metals Handbook, 8th Ed., American Soc. Metals, 1961 and MHW Final Safety Analysis Report for LES 8/9, General Electric document GEMS-419, Vol I (March 1975).

12. Southern Research Institute Data on AVCO Billet 889.

13. Paper presented at "Light-Weight Radioisotope Heater Unit (LWRHU) for Galileo (GLL)," R. E. Tate, Ed., Final Design Review Meeting, Aug. 27, 1980, Los Alamos National Laboratory, Los Alamos, NM 87545.

14. A. Schock, "Light-Weight Radioisotope Heater Unit," FSEC report ESD-217-81/181 (April 1981).

15. D. E. Peterson and J. S. Starzynski, "Reentry Thermal Testing of Light Weight Radioisotope Heater Units," Los Alamos National Laboratory report, LA-9226, to be published.

16. "Qualification Criteria to Certify a Package for Air Transport for Plutonium," US Nuclear Regulatory Commission report NUREG-0360 (January 1978). 


\section{APPENDIX \\ MOUND FACILITY CONSTRUCTION DRAWINGS}

This appendix consists of reduced copies of the Mound Facility construction drawings for LWRHU components. These drawings are identified as

AYC 790095 through AYC 790101 ,

AYC 790105 through AYC 790106 ,

AYD 790379 through AYD 790380, and

AYC 790381 through AYC 790385.

The versions printed here have been enhanced by ink tracing to improve their clarity. 


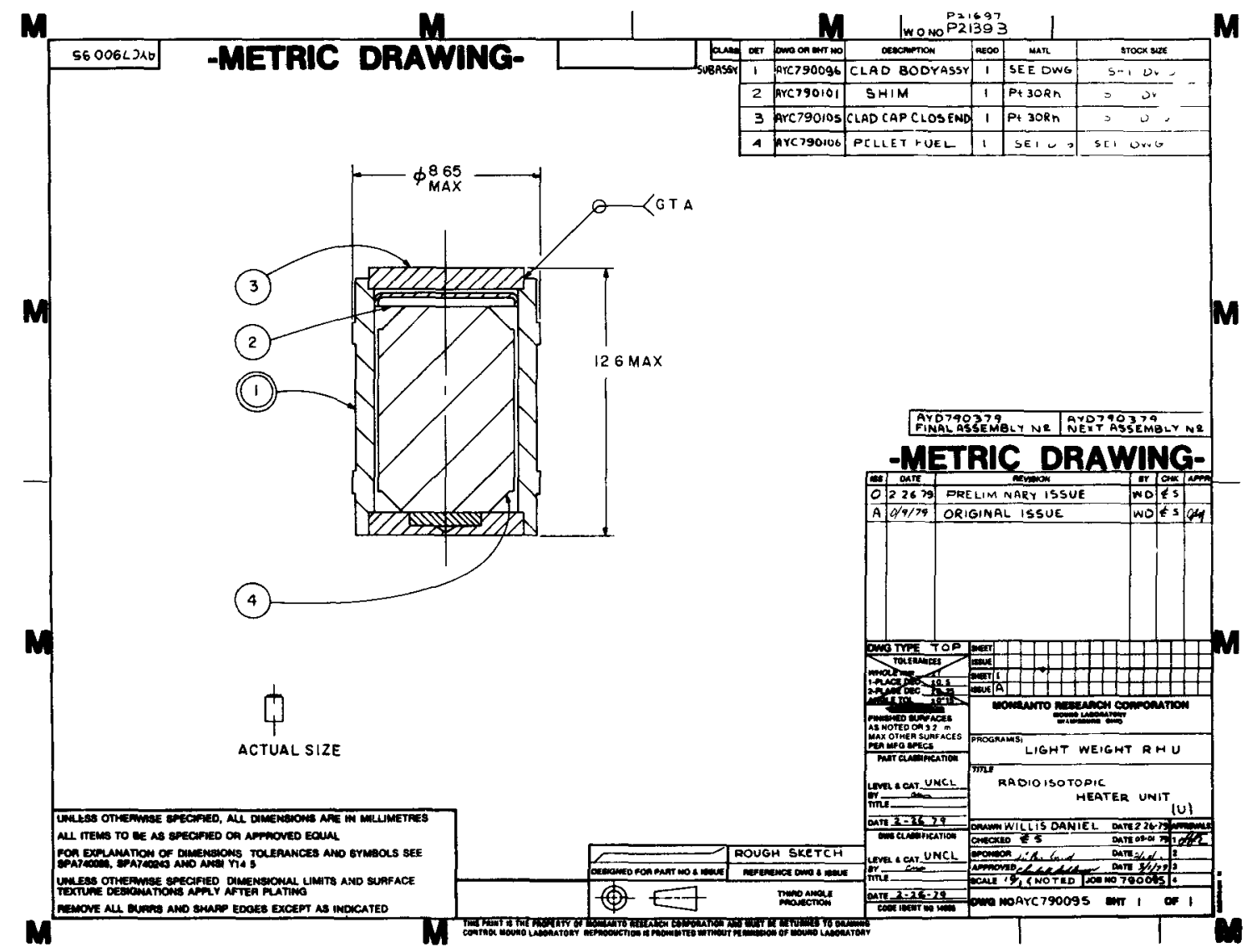




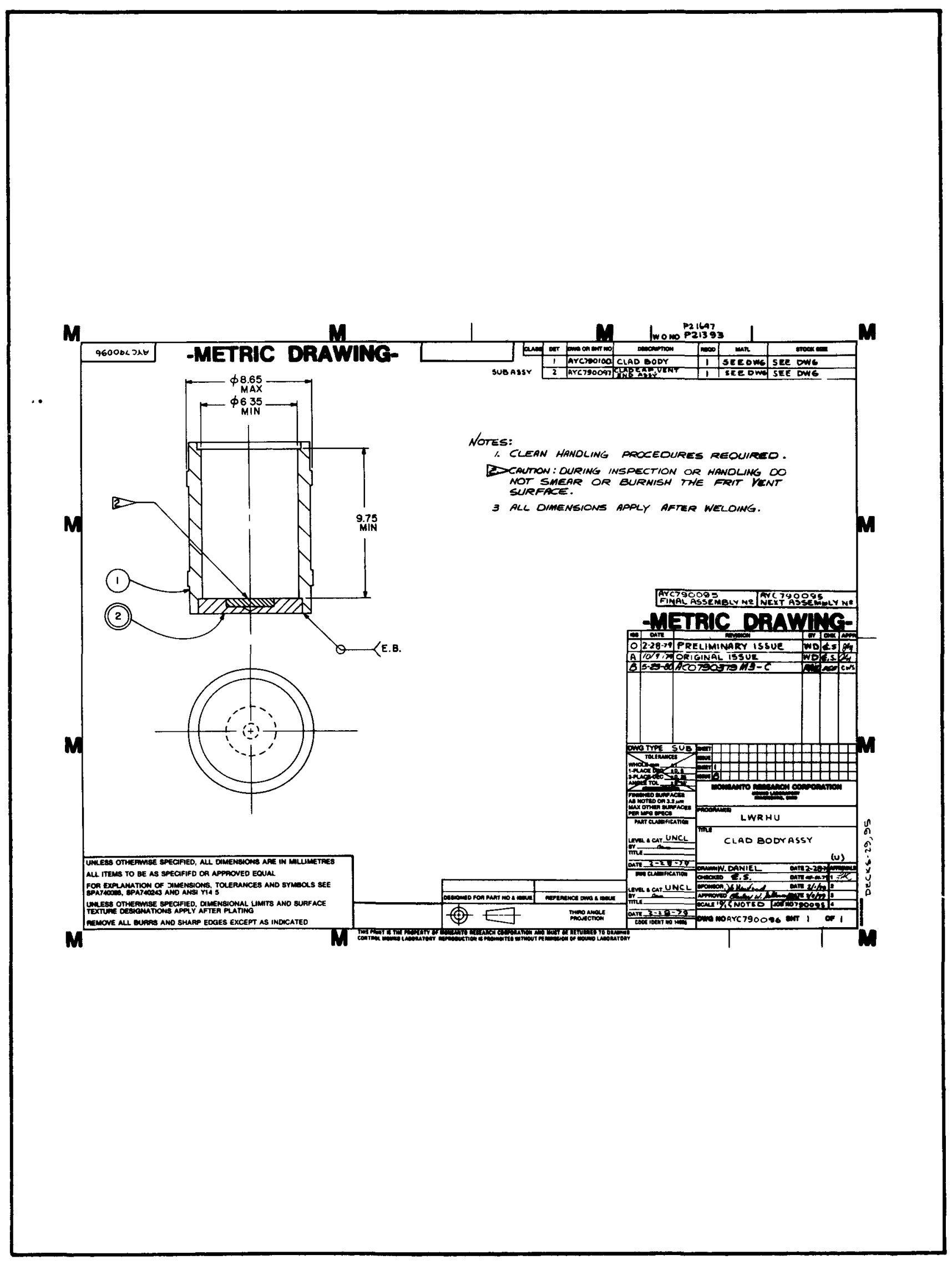




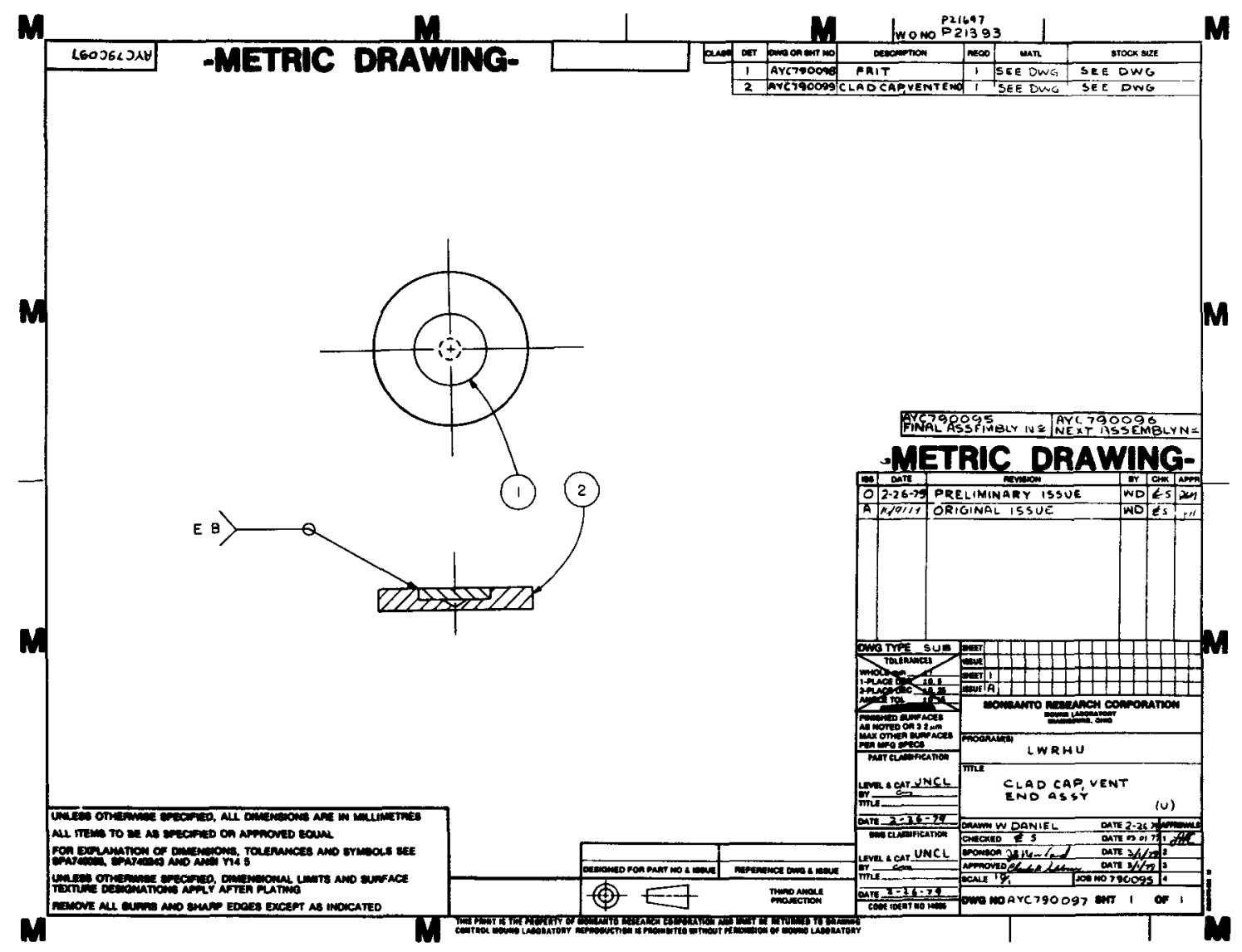




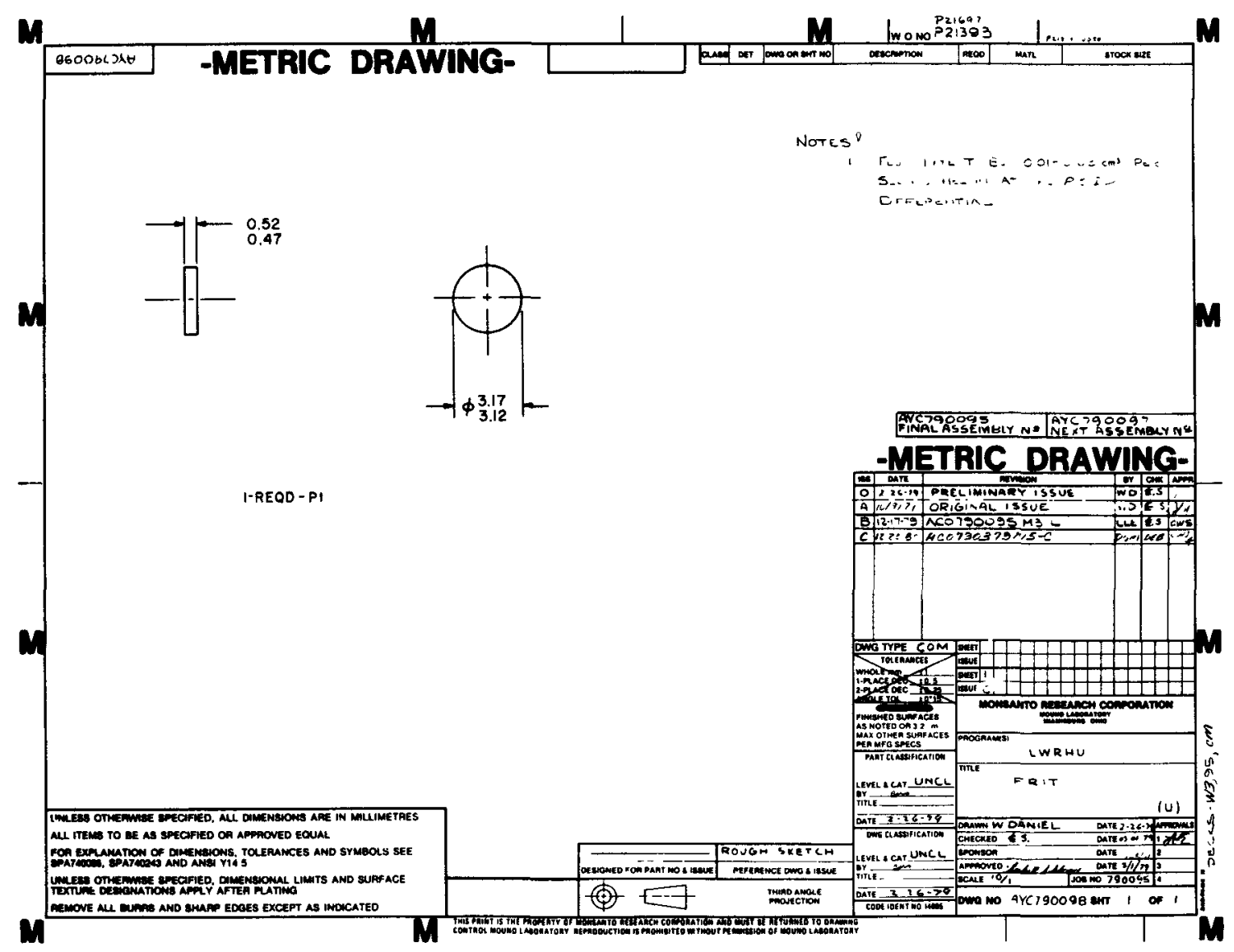




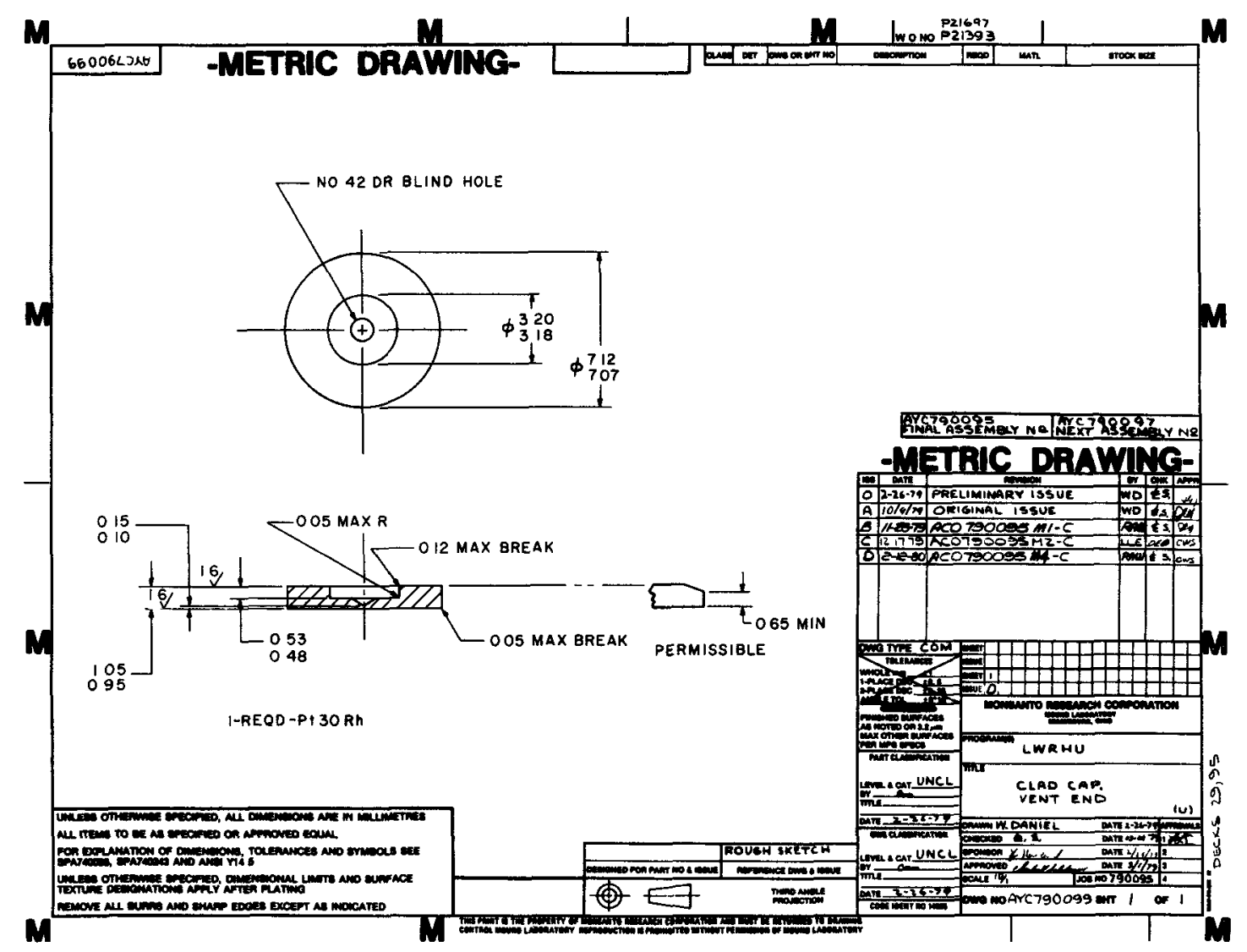




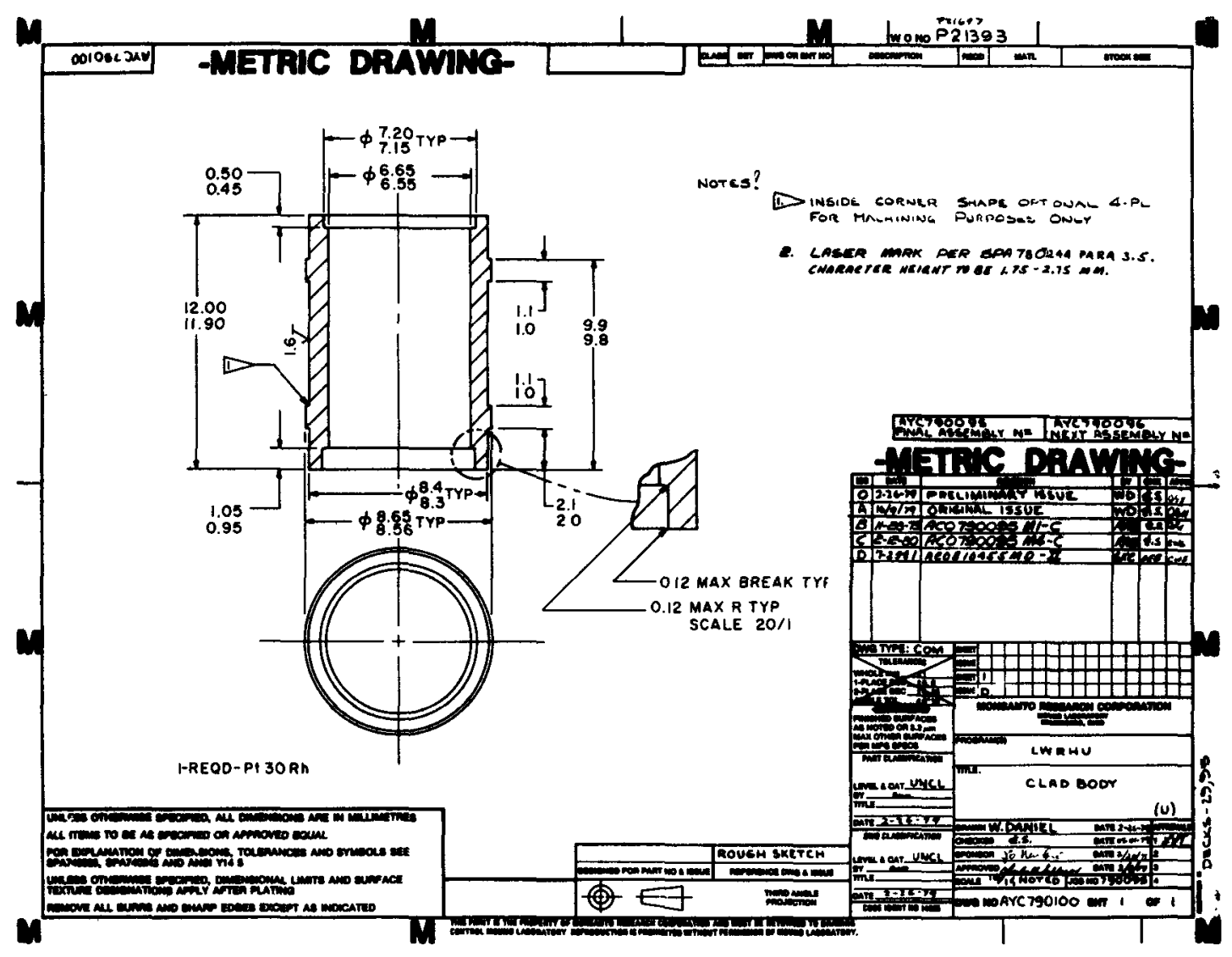




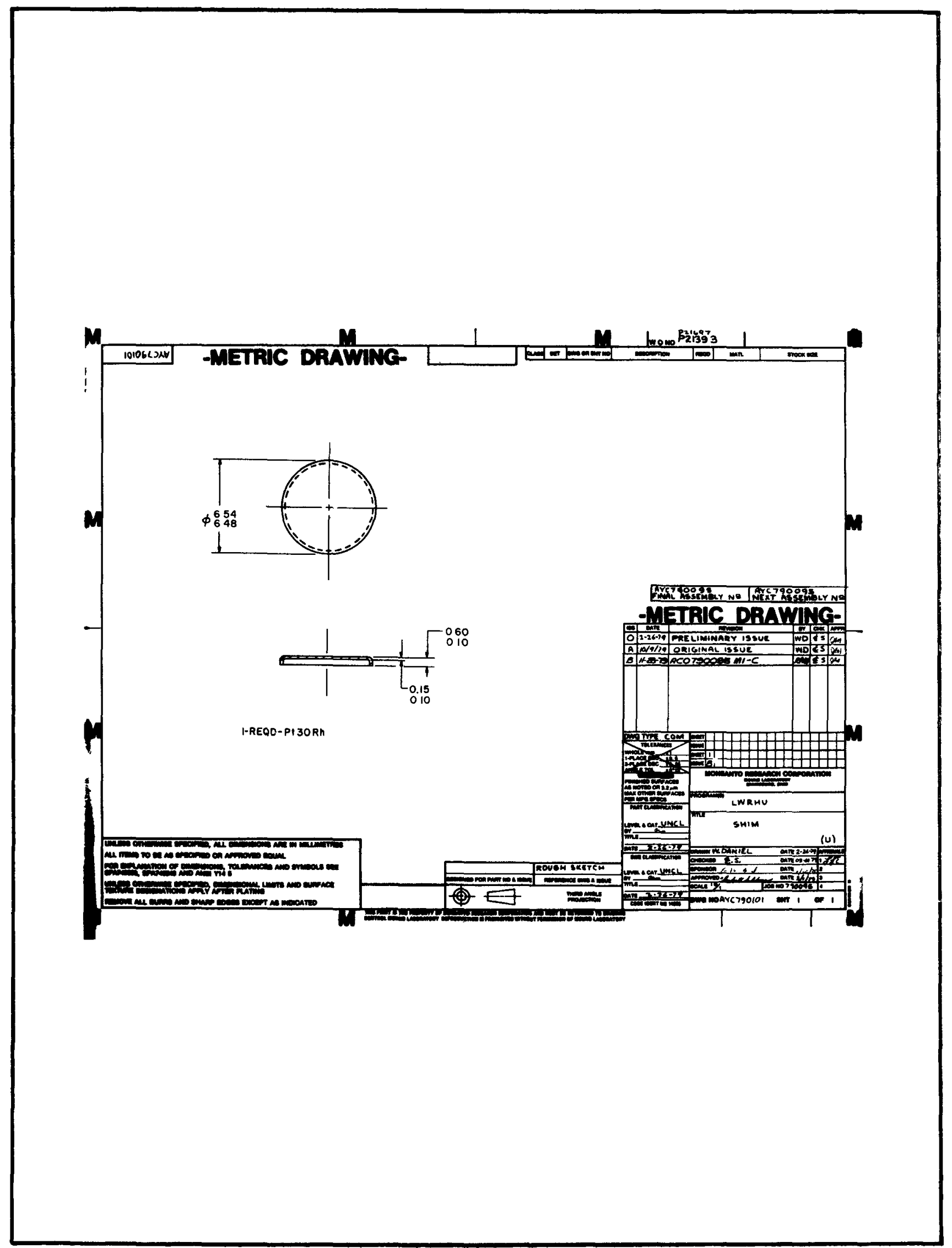




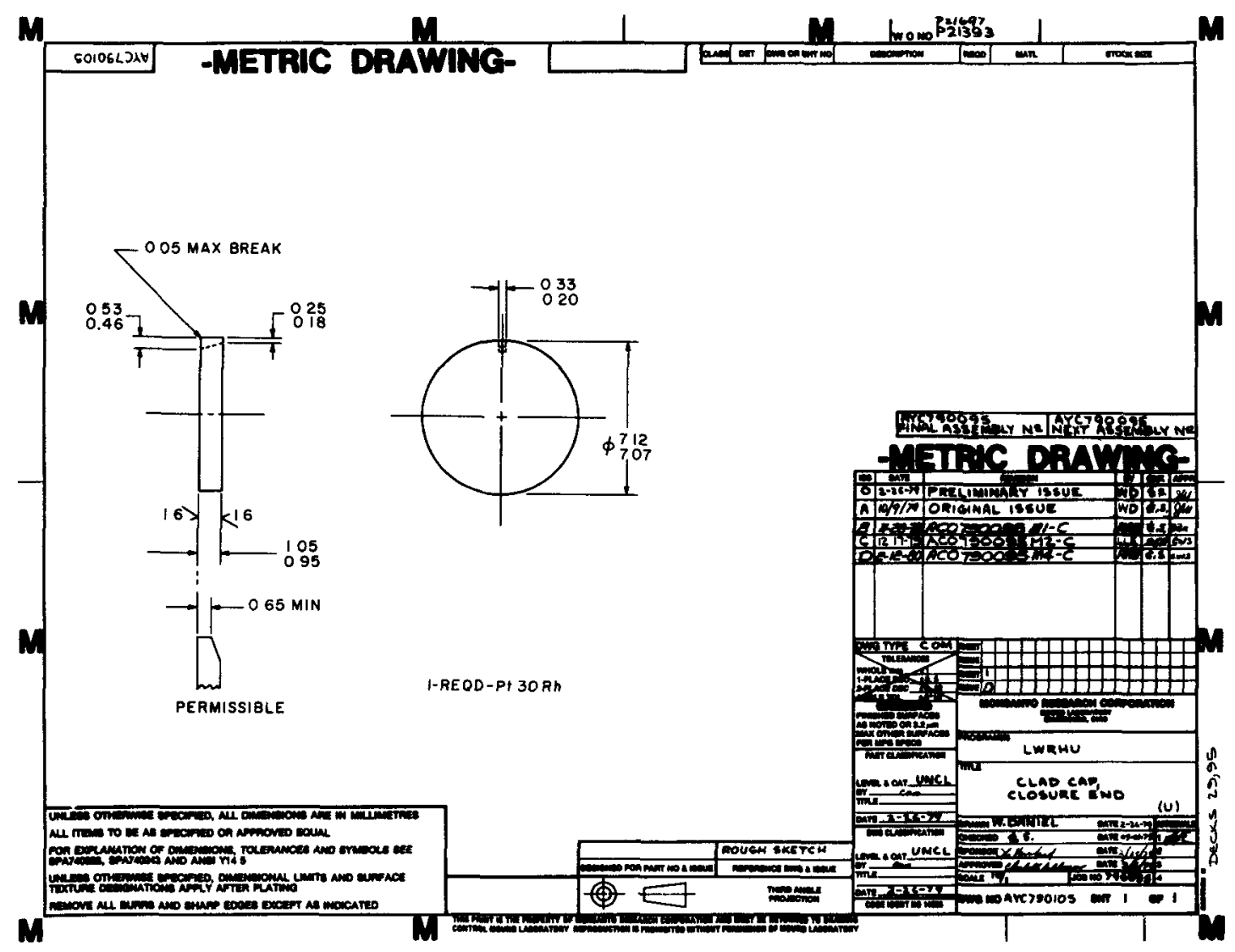




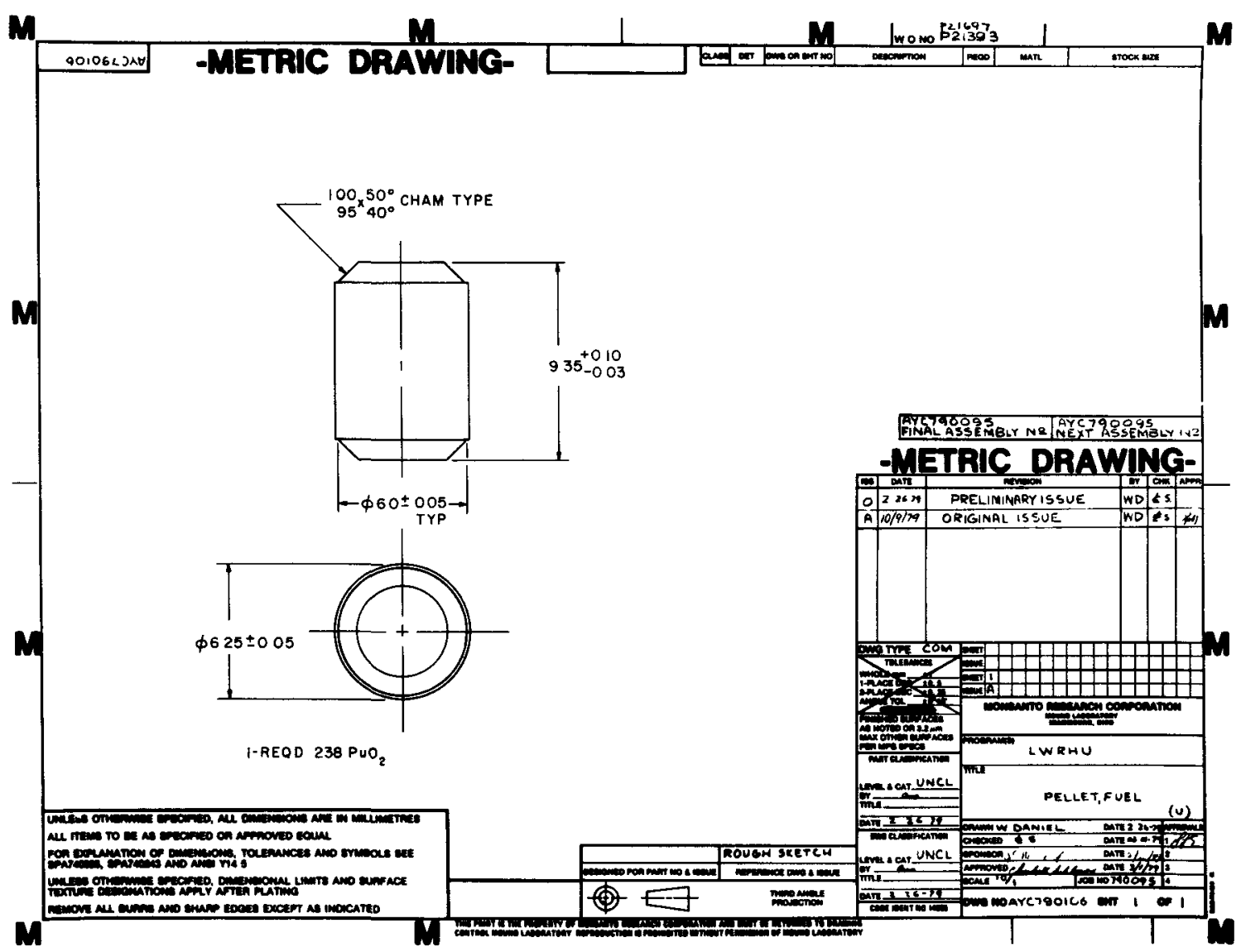




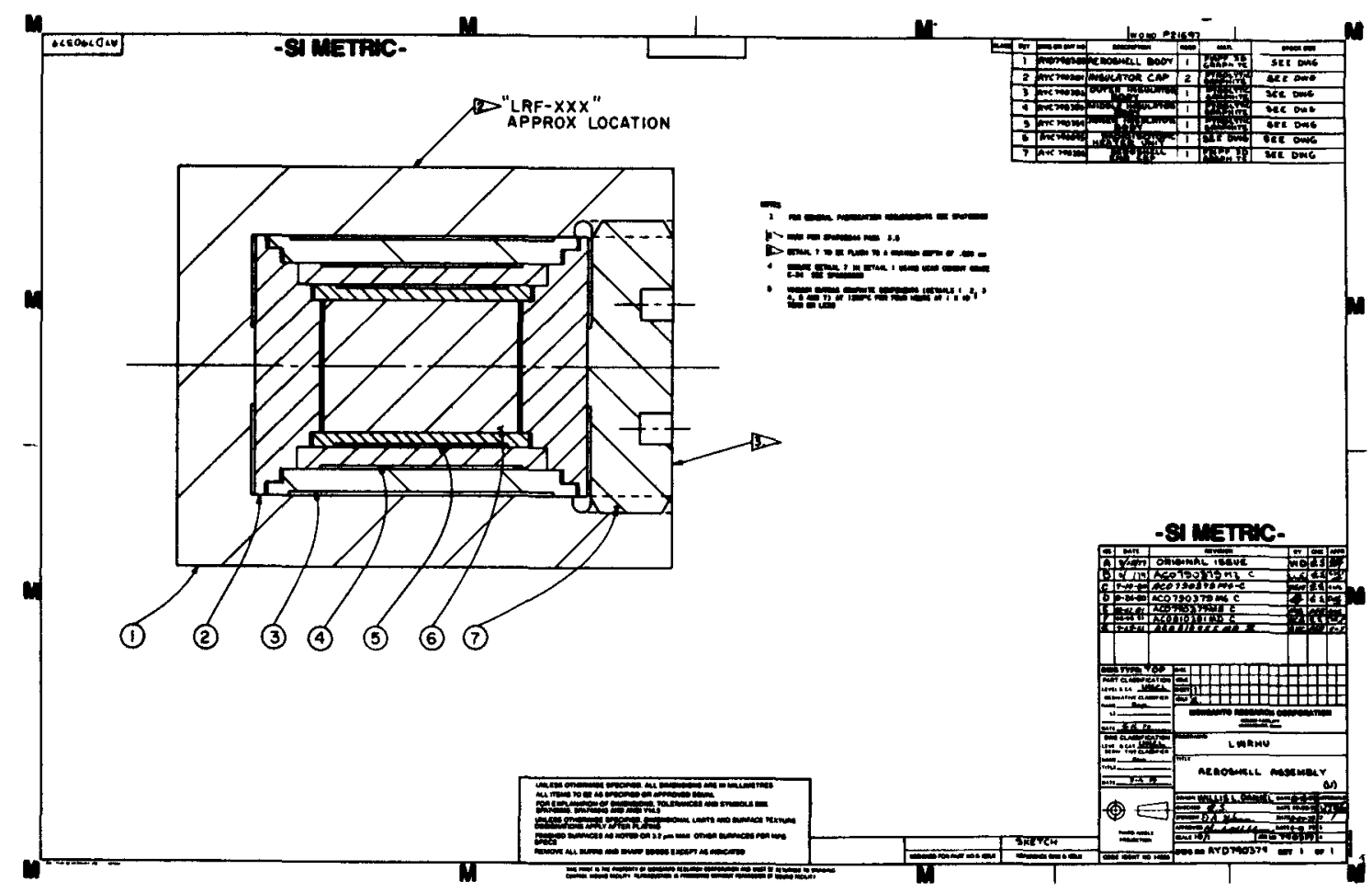




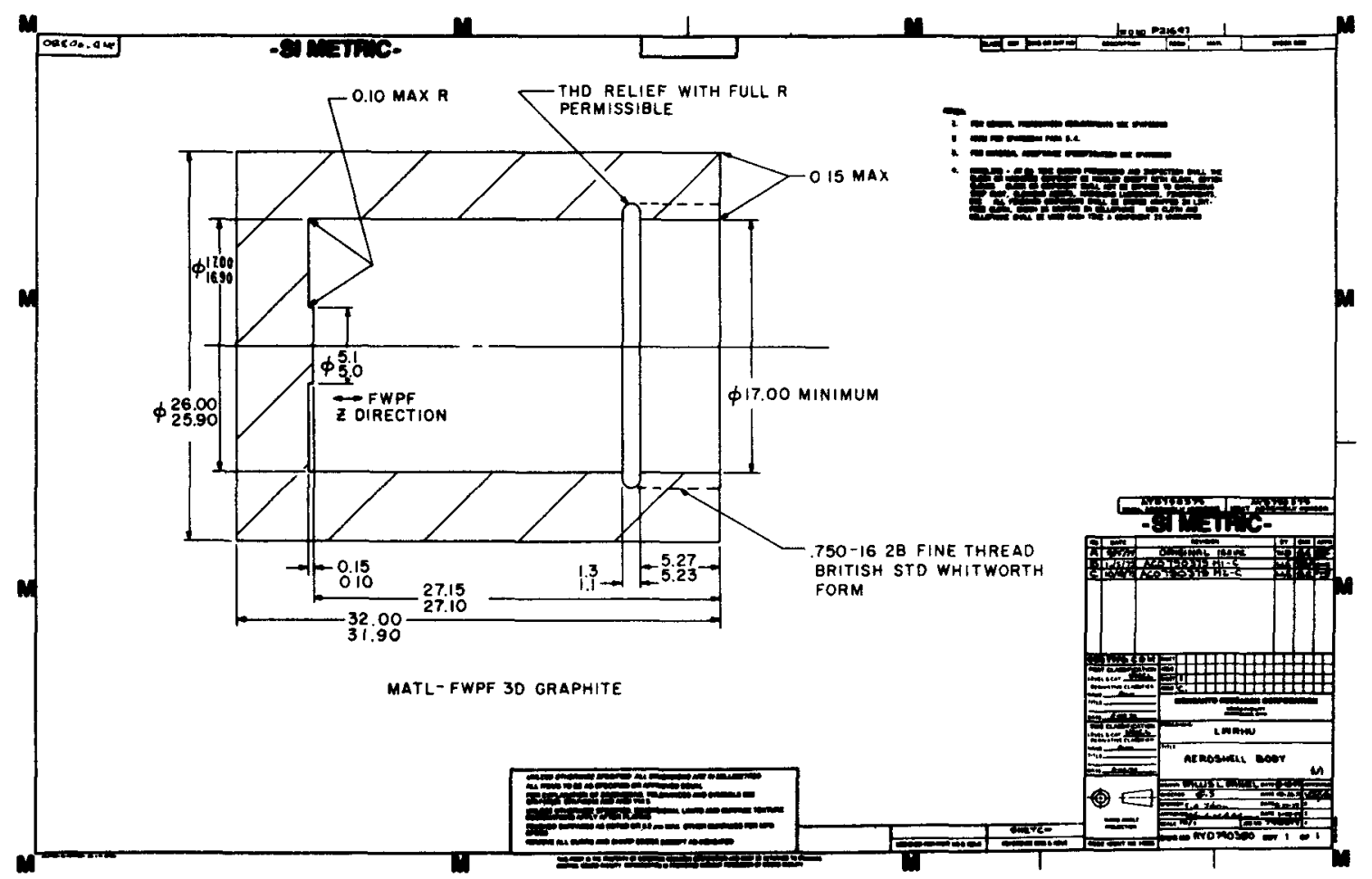




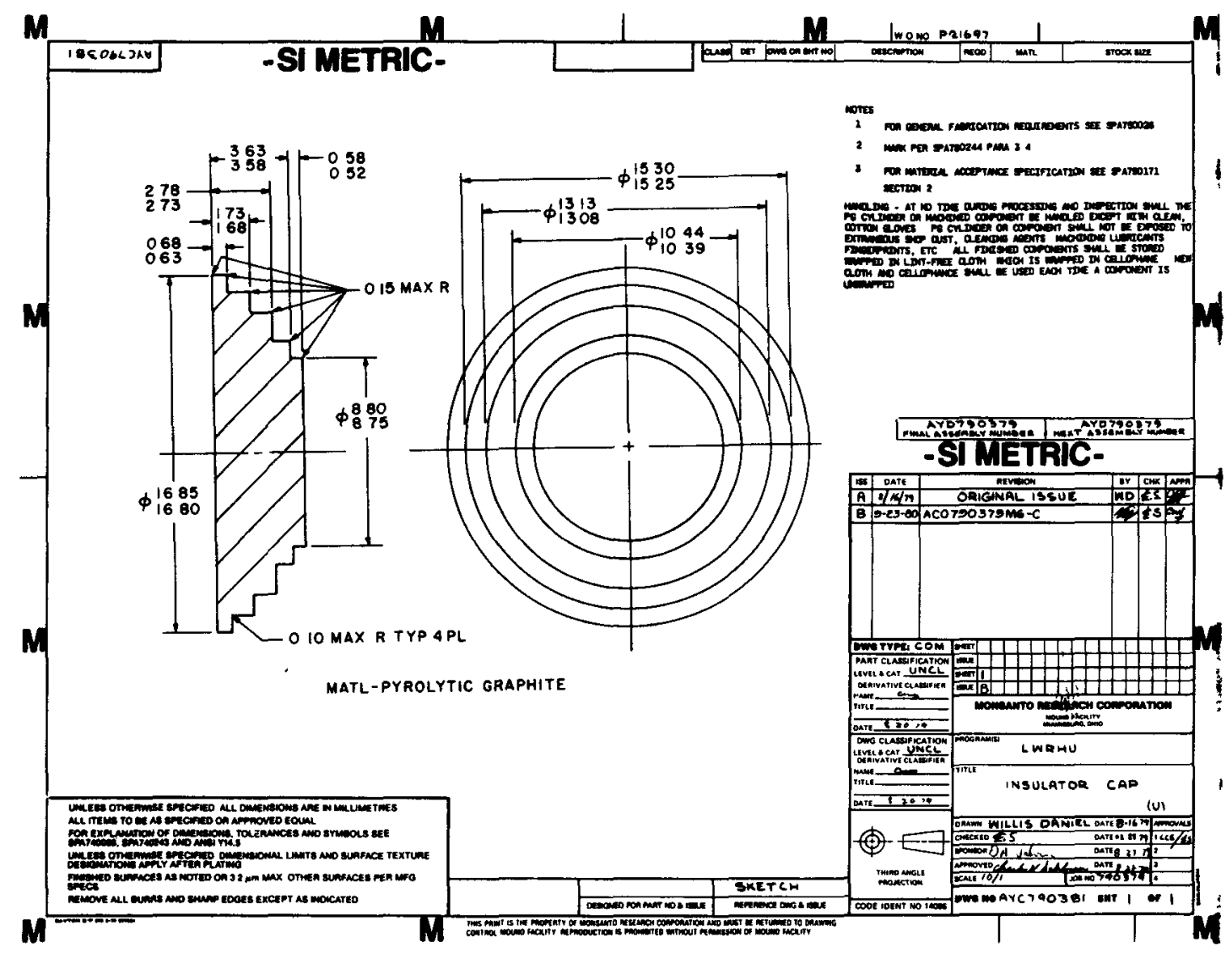




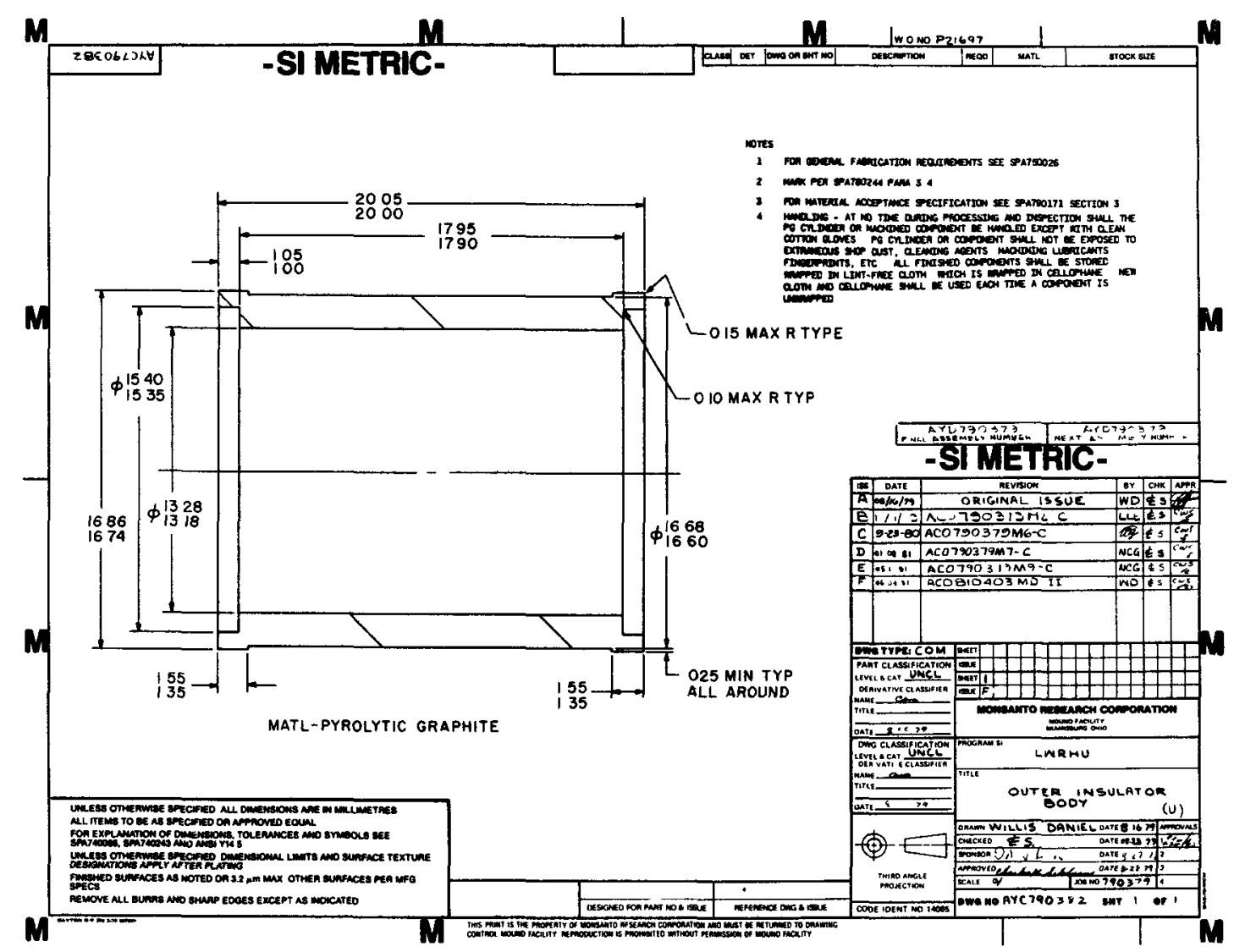




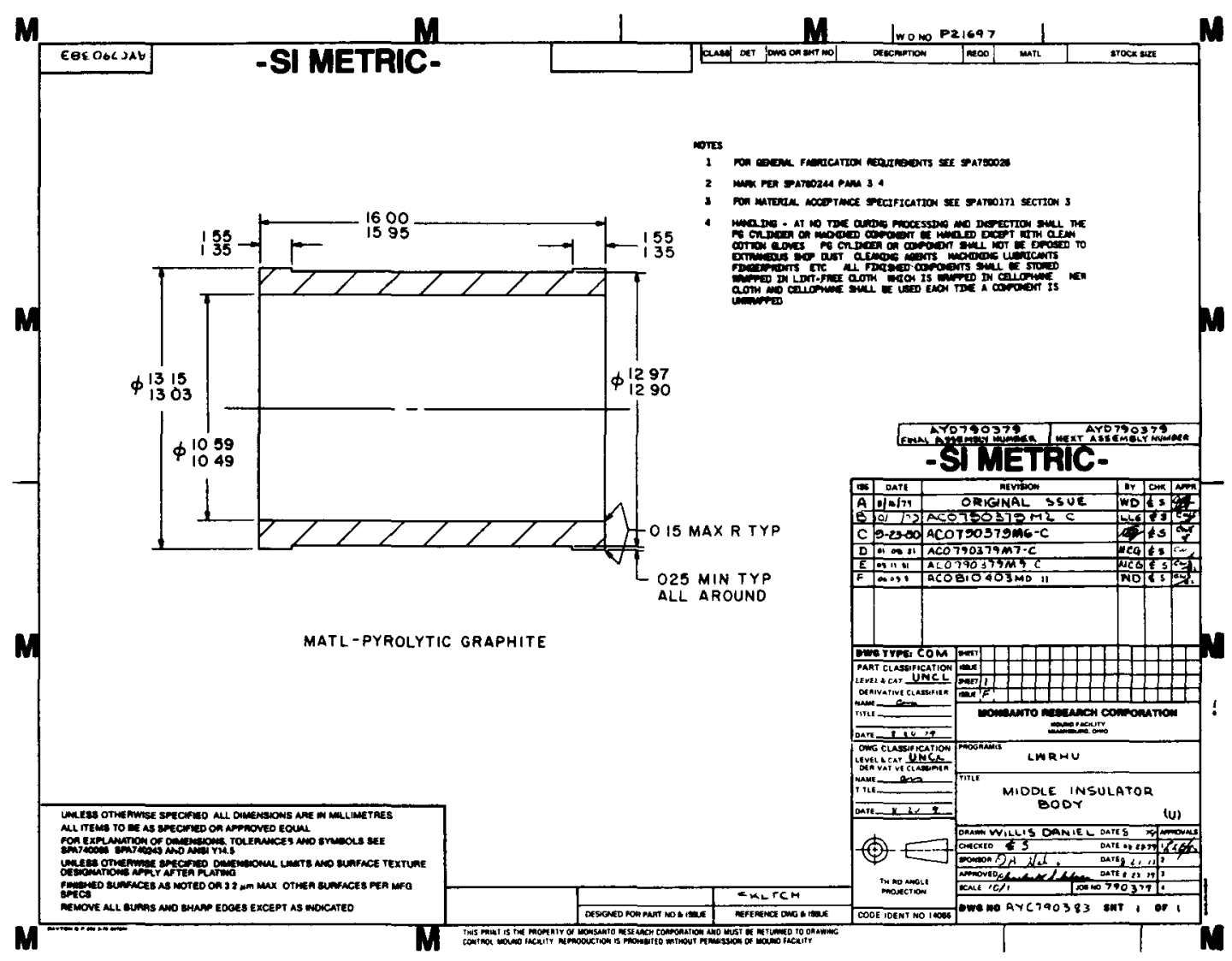




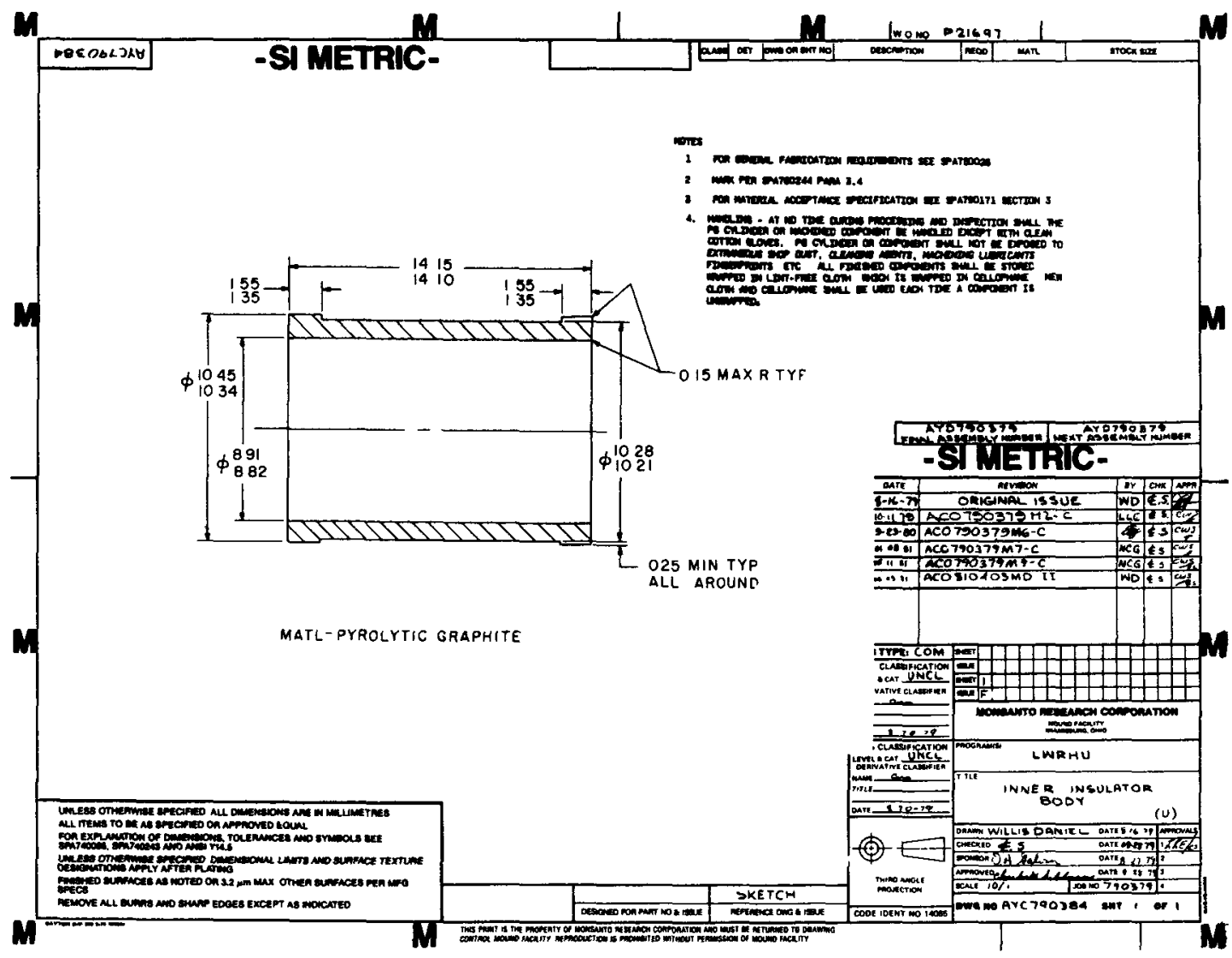




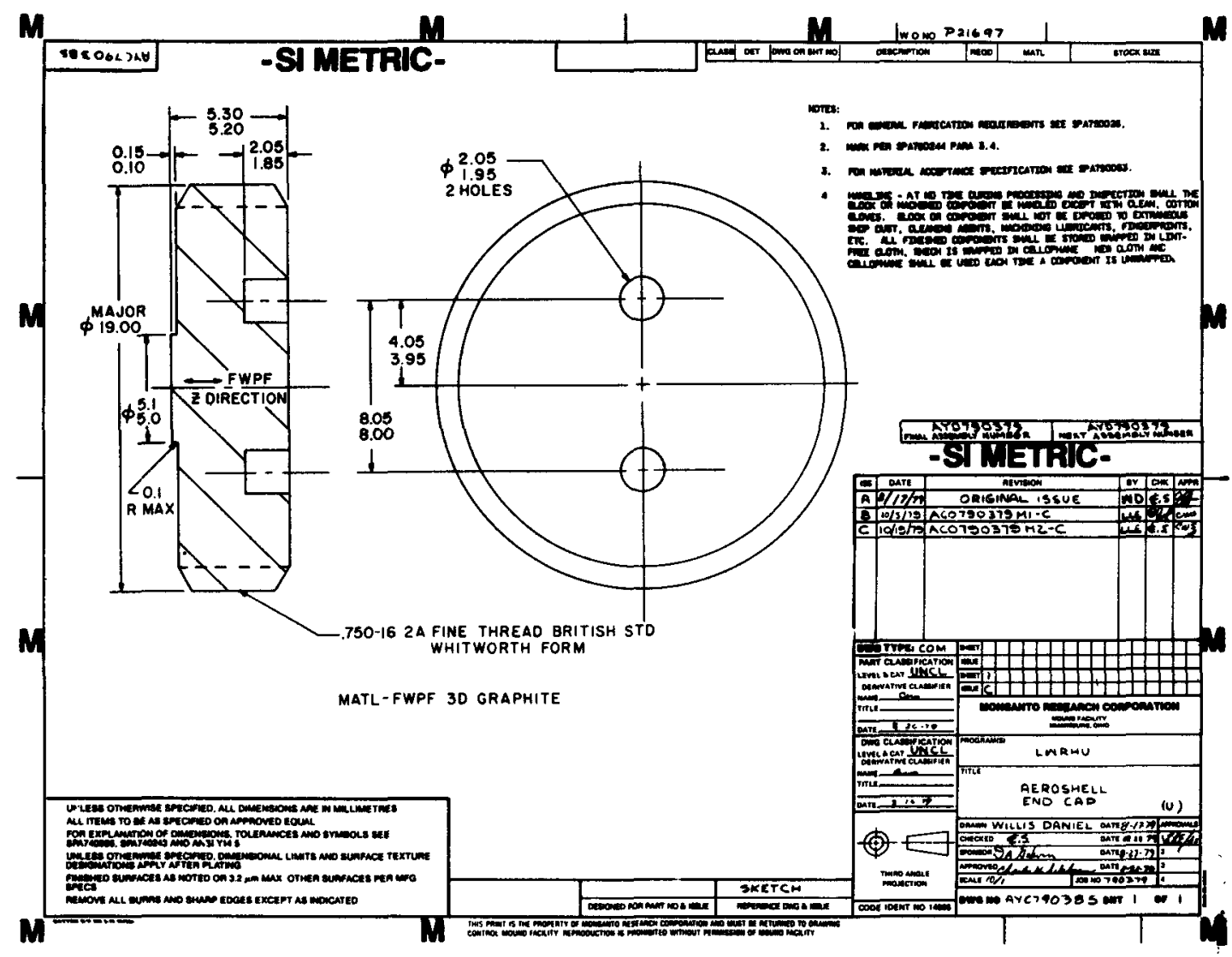

